PAPER

Advances in reference materials and measurement techniques for greenhouse gas atmospheric observations

To cite this article: Paul J Brewer et al 2019 Metrologia 56034006

View the article online for updates and enhancements. 


\title{
Advances in reference materials and measurement techniques for greenhouse gas atmospheric observations
}

\author{
Paul J Brewer $1,16 \oplus$, Jin Seog Kim², Sangil Lee ${ }^{2} \oplus$, Oksana A Tarasova ${ }^{3}$, \\ Joële Viallon ${ }^{4} \oplus$, Edgar Flores ${ }^{4}$, Robert I Wielgosz ${ }^{4}$, Takuya Shimosaka ${ }^{5}{ }^{\circ}$, \\ Sergey Assonov ${ }^{6}{ }^{\circ}$, Colin E Allison ${ }^{7}{ }^{\infty}$, Adriaan M H van der Veen ${ }^{8}{ }^{\circ}$, \\ Brad Hall ${ }^{9}$, Andrew M Crotwell ${ }^{9,10}$, George C Rhoderick ${ }^{11}$, Joseph T Hodges ${ }^{11}$, \\ Joachim Mohn ${ }^{12}$ (I), Christoph Zellweger ${ }^{12}$, Heiko Moossen ${ }^{13}$ (D), \\ Volker Ebert ${ }^{14}$ and David W T Griffith ${ }^{15}$ [D \\ 1 National Physical Laboratory, Hampton Road, Teddington, Middlesex TW11 0LW, United Kingdom \\ 2 Korea Research Institute of Standards and Science (KRISS), Center for Gas Analysis, 267 Gajeong-ro \\ Yuseong-gu, Daejeon 34113, Republic of Korea \\ 3 World Meteorological Organization, 7bis, avenue de la Paix, Case postale 2300, CH-1211 Geneva 2, \\ Switzerland \\ ${ }^{4}$ Bureau International des Poids et Mesures, Pavillon de Breteuil, F-92312 Sèvres Cedex, France \\ 5 National Metrology Institute of Japan, 1-1-1 Umezono, Tsukuba, Ibaraki 305-8563, Japan \\ 6 International Atomic Energy Agency, Vienna International Centre, PO Box 100, 1400 Vienna, Austria \\ 7 CSIRO Climate Science Centre, Oceans and Atmosphere, Aspendale, Victoria 3195, Australia \\ ${ }^{8}$ Van Swinden Laboratorium, Chemistry Group, Thijsseweg 11, 2629 JA Delft, The Netherlands \\ 9 National Oceanic and Atmospheric Administration, 325 Broadway, Mail Stop R.GMD1, Boulder, \\ CO 80305, United States of America \\ 10 Cooperative Institute for Research in Environmental Sciences, University of Colorado, Boulder, \\ CO 80309, United States of America \\ 11 National Institute of Standards and Technology, 100 Bureau Drive, MS-8393 Gaithersburg, \\ MD 20899-8393, United States of America \\ 12 Empa, Laboratory for Air Pollution/Environmental Technology, Überlandstr. 129, 8600 Dübendorf, \\ Switzerland \\ 13 Max Planck Institute for Biogeochemistry, Hans-Knoell-Str. 10, 07745 Jena, Germany \\ ${ }^{14}$ Physikalisch-Technische Bundesanstalt, Bundesallee 100, 38116 Braunschweig, Germany \\ 15 University of Wollongong, Northfields Ave, Wollongong NSW 2522, Australia \\ E-mail: paul.brewer@npl.co.uk
}

Received 21 December 2018, revised 15 March 2019

Accepted for publication 1 April 2019

Published 16 May 2019

\begin{abstract}
We present the global research landscape which aims to deliver a measurement infrastructure to underpin atmospheric observations of key greenhouse gases governing changes in the Earth's climate. These measurements present a significant challenge to the metrological community, analytical laboratories and major producers of reference materials. The review focuses on the progress made in the Gas Analysis Working Group of the Consultative Committee for Amount of Substance: Metrology in Chemistry and Biology (CCQM-GAWG) in establishing the primary realisation of the amount-of-substance fraction for carbon dioxide, methane and nitrous oxide in an air matrix. It also focuses on the importance of providing traceable measurements of isotopic composition of these components for commutability of reference materials and for isotope ratio measurements for greenhouse gas source attribution. The review examines the developments in the Global Atmosphere Watch (GAW) Programme
\end{abstract}

\footnotetext{
${ }^{16}$ Author to whom any correspondence should be addressed.
} 
of the World Meteorological Organization (WMO) for providing the framework for the development and implementation of integrated greenhouse gas observations, which is vital for understanding the global carbon cycle and the role greenhouse gases play in climate change. The developments in analytical techniques are also discussed which have shaped the direction of the metrology required to meet the evolving and future needs of stakeholders.

Keywords: metrology, traceability, greenhouse gas, atmospheric observations, spectroscopy, stable isotopes, calibration

(Some figures may appear in colour only in the online journal)

\section{Introduction}

Industrial and domestic activities have been recognised by the Kyoto Protocol [1] and more recently by the Conference of Parties (COP21) [2] as being major contributing sources to one of the greatest risks to society, climate change [3]. To prevent stark changes to the Earth's climate, emissions of key greenhouse gases such as carbon dioxide, methane and nitrous oxide must be reduced. Abundances of carbon dioxide and methane in the atmosphere are at the highest they have been in the past 3 million years and this is mainly attributable to human activities [4]. In 2015, the World Meteorological Organization (WMO) reported that the global average amountof-substance (later abbreviated to amount) fraction of carbon dioxide exceeded the symbolic $400 \mu \mathrm{mol} \mathrm{mol}^{-1}$ threshold and it is unlikely to return below it in our lifetimes [5-8]. Current levels of methane are nearly triple the pre-industrial value $[7,9,10]$.

Estimating greenhouse gas emissions based on atmospheric observations is challenging because it requires accurate, highprecision measurements of amount fraction. Measurements made at different locations and by different laboratories must be highly consistent, with minimal bias introduced through sampling and calibration. The Global Atmosphere Watch (GAW) Programme within the WMO has provided a framework for the development and implementation of integrated greenhouse gas observations since 1989 [11]. In the GAW programme, consistency is targeted through traceability to unique scales that are maintained over long time periods. Further, GAW has adopted goals for network compatibility, which stem from maximum bias tolerance among networks and data providers. These requirements make this area specially challenging, as measurement standards are needed with very small uncertainty and good long-term stability to underpin trends in climate monitoring measurement results.

Since its formation, the Gas Analysis Working Group of the Consultative Committee for Amount of Substance: Metrology in Chemistry and Biology (CCQM-GAWG) has made prodigious strides towards ensuring international comparability, meeting the needs of stakeholders and advancing measurement science. An area of notable achievement is the development of gas reference materials and analytical techniques for underpinning atmospheric composition measurements of greenhouse gases to address evolving measurement requirements [12]. In 2010 the WMO became a signatory of the
International Committee for Weights and Measures' Mutual Recognition Arrangement (CIPM-MRA) [13]. The partnership formed between the WMO's designated institutes and the CCQM-GAWG has benefitted both the metrology and atmospheric monitoring communities. Key comparisons organised by the CCQM-GAWG provide a useful link between the primary standards used in the WMO-GAW network and the SI and an on-going framework for assessing drift in these measurements systems over time. The metrology community has benefitted substantially from the experience and research input from expert laboratories designated by the WMO which has led to significant advances in measurement science. This partnership is striving to provide a metrology infrastructure to support scientific research related to greenhouse gas sources and sinks and address real world applications.

Measurements of isotopic composition are also needed to help discriminate anthropogenic emissions from natural contributions and to provide important information about the processes involved in the sources, sinks and chemical transformations of these components. The anthropogenic component of these is very difficult to assess (let alone be split into the various emission sources) because of the very significant, temporally and spatially varying natural sources and sinks [14]. Abundance ratios of isotopocules are regarded as useful parameters to infer the origin and production-consumption mechanisms of these substances and to estimate their global budget, but the signals are small and thus an accurate and long-term stable calibration scheme is required. The International Atomic Energy Agency (IAEA), signatory of the CIPM-MRA since 2010, alongside several other organisations and National Metrology Institutes (NMIs), provides the highest-level reference materials for hydrogen, carbon, nitrogen, oxygen and sulphur isotopes. It is recognised as a custodian for stable isotope scales of elements hydrogen, carbon, nitrogen, oxygen and sulphur [15]. Various reference materials produced by other providers are traceable to reference materials from the IAEA. Reference materials for isotope ratio are currently the only approved traceability exception within the CIPM MRA.

Stable isotope ratio mass spectrometry (IRMS) is still the most precise tool for measuring stable isotope ratios but the introduction of various spectroscopic techniques (collectively known as isotope ratio infrared spectroscopy, or IRIS), has revolutionised the measurement of key greenhouse gas components in air by enabling real time in situ field measurements. 
These measurements help identify and quantify sources and sinks at local, regional, and global scales, and contribute to the understanding of their relative impacts on atmospheric concentrations. IRIS instruments usually report values as amount fractions of individual isotopocules, and for the most accurate measurements of isotope ratio and amount fraction, require calibration gases that have their isotope ratios assigned to at least (preferably better than) the analytical precision of the technique. This need has triggered development of gas reference materials that provide traceability for all stable isotope ratio measurements to the primary scales.

This review focuses on the developments in reference material production and measurement techniques for underpinning atmospheric amount fraction measurements of three key greenhouse gases (carbon dioxide, methane and nitrous oxide) as well as the isotopic composition of these components for source attribution. Current practices and developments for the primary realisation within the CCQM-GAWG, and the WMO-GAW programme are reviewed as well as how the state of the art in measurement techniques for accurate greenhouse gas measurement has evolved in recent years.

\section{Developments in the CCQM-GAWG}

Members of the CCQM-GAWG have expertise in the analysis of gas composition, the preparation of gas reference materials [16], and maintaining national measurement standards. The most accurate gas reference materials value assigned for the amount fraction of their components are usually realised by gravimetric preparation, where the quantity of interest is the amount fraction of the component in the gas mixture. The lowest measurement uncertainties are required for the atmospheric observations of greenhouse gases, with reference materials for carbon dioxide, methane and nitrous oxide in air being of major interest. Section 2.1 shows the progress made towards improved comparability of the reference materials maintained by the NMIs. Section 2.2 summarises the state of the art in gas mixture preparation, assignment of amount fractions and evaluation of the associated measurement uncertainty. In the quest for low uncertainties for measurements of atmospheric greenhouse gas amount fractions, the isotopic composition of gas reference materials is a subject of growing concern. Section 2.3 highlights how the effects of the isotopic composition were observed in comparisons using spectroscopic methods, and reviews value assignment procedures to ensure compatibility and commutability (the ability of a gas reference material to act as an air sample in a specific air monitoring instrument) of gas reference materials.

\subsection{Key comparisons and state of the art in comparability}

Reference materials prepared by NMIs using gravimetric methods described in section 2.2 undergo a careful series of verification experiments to ensure the traceability of the amount fraction to the SI with the lowest possible uncertainty [17]. Ultimately, they are compared during key comparisons organised under the CIPM-MRA [13]. A key comparison establishes the equivalence of the NMIs' reference materials at the highest possible metrological level and confirms as far as is possible the complete understanding of the methods used by participants. A specificity of CIPM key comparisons is the choice of one or more key comparisons reference value (KCRV) and uncertainty, considered to be the best estimate(s) of the SI-traceable value and uncertainty that can be demonstrated for the amount fraction measured.

A number of such comparisons have already been undertaken by members of the CCQM-GAWG to underpin gas reference materials of the three major greenhouse gases in air. A pilot study was first conducted in 2003 on carbon dioxide and methane in synthetic air (CCQM-P41 [18, 19]). It used two different models of comparison. The first with an ensemble of reference materials prepared by the pilot laboratory and sent to other participants (Part 1) and the second with each participant sending their prepared reference materials to a central facility (Part 2). The second scheme allows the reference value for cylinders to be calculated from the largest consistent set of reference materials and has the advantage of reducing uncertainties of the reference value, as demonstrated for example with carbon dioxide in air comparisons (now $0.05 \mu \mathrm{mol} \mathrm{mol}^{-1}$ (CCQM-K120.a 2018 [20]) reduced from $0.2 \mu \mathrm{mol} \mathrm{mol}{ }^{-1}$ (CCQM-K52, 2006 [21])) some ten years previously.

For these comparisons to fulfil the above principles, there are a number of experimental and measurement conditions which need to be agreed between participants and laid down in the comparison protocol. These include a defined time scale, agreement on the amount fraction in the reference materials, appropriate analytical techniques acting as comparators, agreed mathematical treatment of the results, and sometimes defined requirements on the composition of the gas mixtures prepared by participants.

2.1.1. Improved analytical techniques used as comparators. Comparisons which follow the model where all participants send their reference materials to a central facility are most beneficial when the instrumentation used for the analysis is specific to the component, unbiased towards potential differences in the reference materials other than the amount fraction and can be operated in a way to minimise the variance of measurements during the time required to conduct the comparison. The aim is to perform analytical measurements that produce an analytical uncertainty that is negligible compared to the uncertainties on reference materials declared by participants.

Component specificity, a requirement of measurements in whole air, is normally achieved by using the same instrumentation found in air monitoring laboratories, as described in section 4. GC-FID was used during the methane and carbon dioxide key comparisons $[20,22]$ and GC-ECD during the nitrous oxide key comparison [23]. As GC instruments are known to present drifts on a time scale of about an hour, the pilot laboratory normally uses drift correction with a control cylinder and optimises its measurement sequence to obtain minimum repeatability uncertainty. Relative standard uncertainties of the order of $0.02 \%$ were achieved on methane 
measurements during CCQM-K82, and between $0.003 \%$ and $0.01 \%$ on carbon dioxide during CCQM-K120.

Another beneficial practice introduced during CCQMK82 was to measure all submitted reference materials using two analytical techniques differing as much as possible in their principle; this increases the robustness of the comparison towards incidents, and most importantly, towards potential method-specific biases. In this way, techniques relying on absorption of infrared light by the component were also selected: CRDS during CCQM-K82, Fourier-transform infrared (FTIR) during CCQM-K120, and TDLAS to be used in the upcoming comparison on nitrous oxide (CCQM-K68.2019). These techniques are normally characterised with better shortterm precisions than GC (section 4.3), which may be mitigated by additional variances due to the time required to compare as many as sixteen reference materials together [20]. They are, however, subject to a specific bias arising from differences in the composition of the matrix (a 'component dependent pressure broadening effect' that drove tight requirements on prepared reference materials during the comparisons). In addition, spectroscopic techniques are normally specific to isotopologues, resulting in biases if the reference materials in a comparison presents different isotopic compositions. This was addressed during CCQM-K120, with a third IRIS instrument introduced to measure carbon dioxide isotope ratios in all reference materials to correct the carbon dioxide amount fractions measured by FTIR.

\subsubsection{Increased constraints on the composition of reference} materials. The property of commutability towards measurement techniques introduced in section 2.3 constitutes a strong requirement during key comparisons as well. Comparisons conducted since 2010 introduced tighter limits on the amount fraction of the main components of synthetic air (nitrogen, oxygen and argon) imposed to participants when preparing their reference materials, to ensure a negligible uncertainty due to the pressure broadening effect. During the validation work performed by the BIPM for CCQM-K82, it could be demonstrated that reference materials of methane prepared by the National Institute of Standards and Technology (NIST) in scrubbed dry air were equivalent to those prepared in synthetic air within the limits imposed by the use of CRDS as the analytical technique [24].

For comparisons of carbon dioxide in air reference materials by spectroscopic techniques such as FTIR used during CCQM-K120, the dependency of the technique to particular carbon dioxide isotopologues was considered. However participants were not asked to select a particular composition when preparing their reference materials. Instead, the pilot laboratory measured the isotopic composition of carbon dioxide in each reference material with an IRIS instrument and successfully corrected amount fraction measurements by FTIR [20].

2.1.3. Calculation of key comparison reference values. The preferred model for comparisons organised by the CCQMGAWG requires the preparation of gas reference materials by each participant at a defined nominal amount fraction. The measurement of all reference materials is carried out by the coordinating laboratory and considered as a set defining a calibration curve for the analytical instrument used as the comparator. The calibration curve is computed from a regression line of the measured values using uncertainties on both axes, following the procedures outlined in ISO 6143:2001 [25]. Gas reference materials from participants which contribute to the key comparison reference value (KCRV) are then selected on the basis of obtaining the largest consistent data set, as demonstrated with the goodness-of-fit parameter. Technical reasons are normally applied for removing outliers, for example a lack of stability reported in the most recent carbon dioxide comparison CCQM-K120 [20]. A KCRV is then determined for each gas reference material by applying the inverse regression equation to the value measured by the pilot laboratory. This allows degrees of equivalence $D_{i}$ to be defined for each participant, as the difference between the submitted value (typically the gravimetric value) and the KCRV, with its associated uncertainty at a $95 \%$ level of confidence.

2.1.4. Improved compatibility over the past ten years. Over the last ten years, improvements in preparation of gravimetric reference materials described in section 2.2 and in the comparison methods resulted in better agreement amongst NMIs. This is most obvious for the methane and carbon dioxide comparisons. Figure 1 compares the results of CCQM-K82 with results from a comparison performed ten years earlier (CCQMP41). The level of agreement amongst reference materials improved by a factor of ten. The standard deviation of results in 2003, around the reference value was $30 \mathrm{nmol} \mathrm{mol}^{-1}$, and $11 \mathrm{nmol} \mathrm{mol}^{-1}$ for a more limited set of reference materials, which improved to $1.8 \mathrm{nmol} \mathrm{mol}^{-1}$ in 2013 .

The most recent carbon dioxide comparison CCQM-K120 also demonstrated improvements in the uncertainty of the reference materials and the comparison method, as displayed in figure 2 with its results compared to the previous exercise CCQM-K52. The improvement is most striking when only participants selected as forming the largest consistent set of reference materials are considered, as indicated in the figure. A similar improvement is expected in the future nitrous oxide comparison to be commenced in 2019 by the BIPM (CCQM-K68.2019).

\subsection{State of the art in gravimetric reference materials}

One of the core capabilities of NMIs in gas analysis is the preparation of gas reference materials for one or several components at a given amount fraction in a well-defined matrix. The composition of these reference materials, expressed in amount fraction $\left(\mathrm{mol} \mathrm{mol}^{-1}\right)$, is traceable to the SI through gravimetric techniques. The preparation involves the transfer of nominally pure starting materials into gas cylinders and is fully described in ISO 6142-1 [26]. The major contributors to the uncertainty of the reference material are the mass of components added, the assessment of purity of the starting materials, determination of the molar mass of the air based on its composition of amounts of oxygen, argon and nitrogen, and the trace levels of other components [27-29]. For the latter, the most important factor in determining the trace levels of contaminants in 


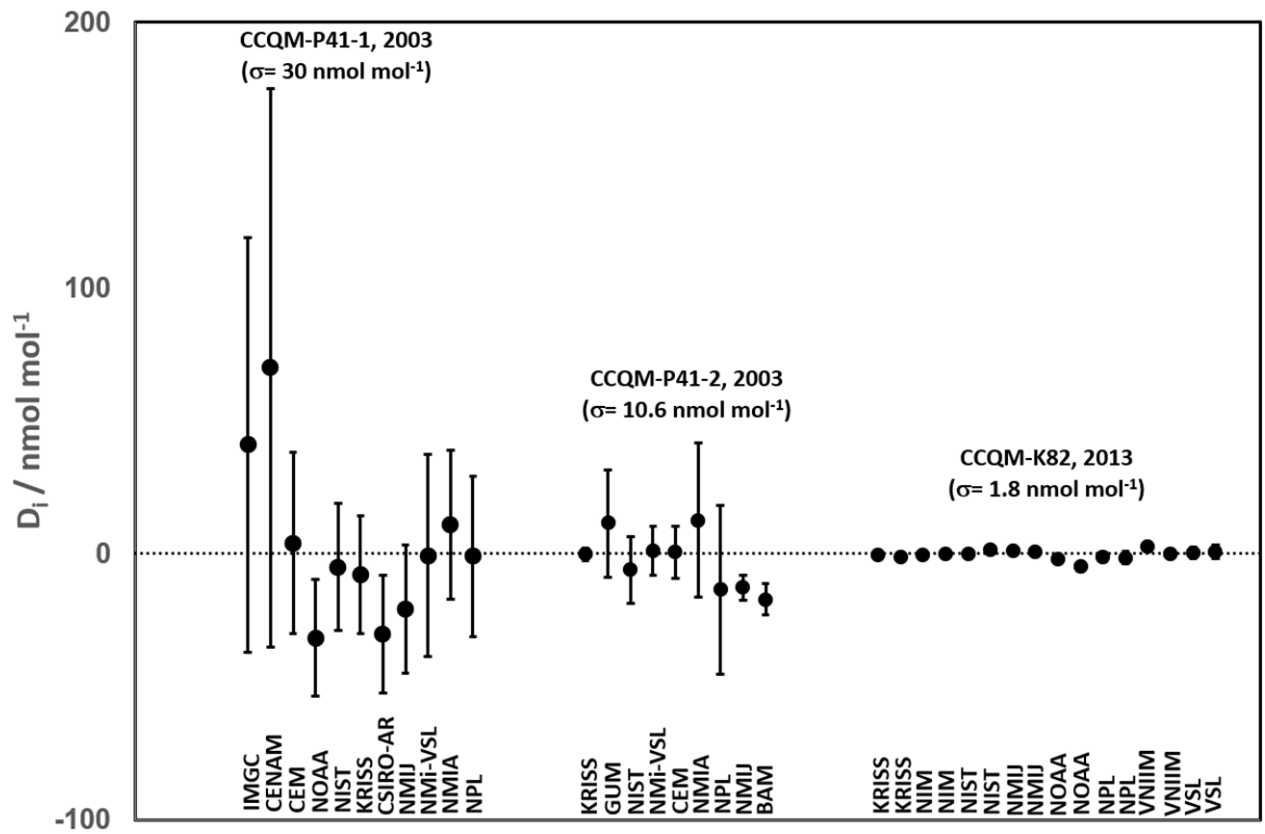

Figure 1. Degree of equivalence between methane in air amount fractions (ambient levels) in the comparisons CCQM-P41 (2003) and CCQM-K82 (2013). The error bar represents the expanded uncertainty at a 95\% level of confidence. For each comparison, the standard deviation $\sigma$ of the degrees of equivalence is indicated.

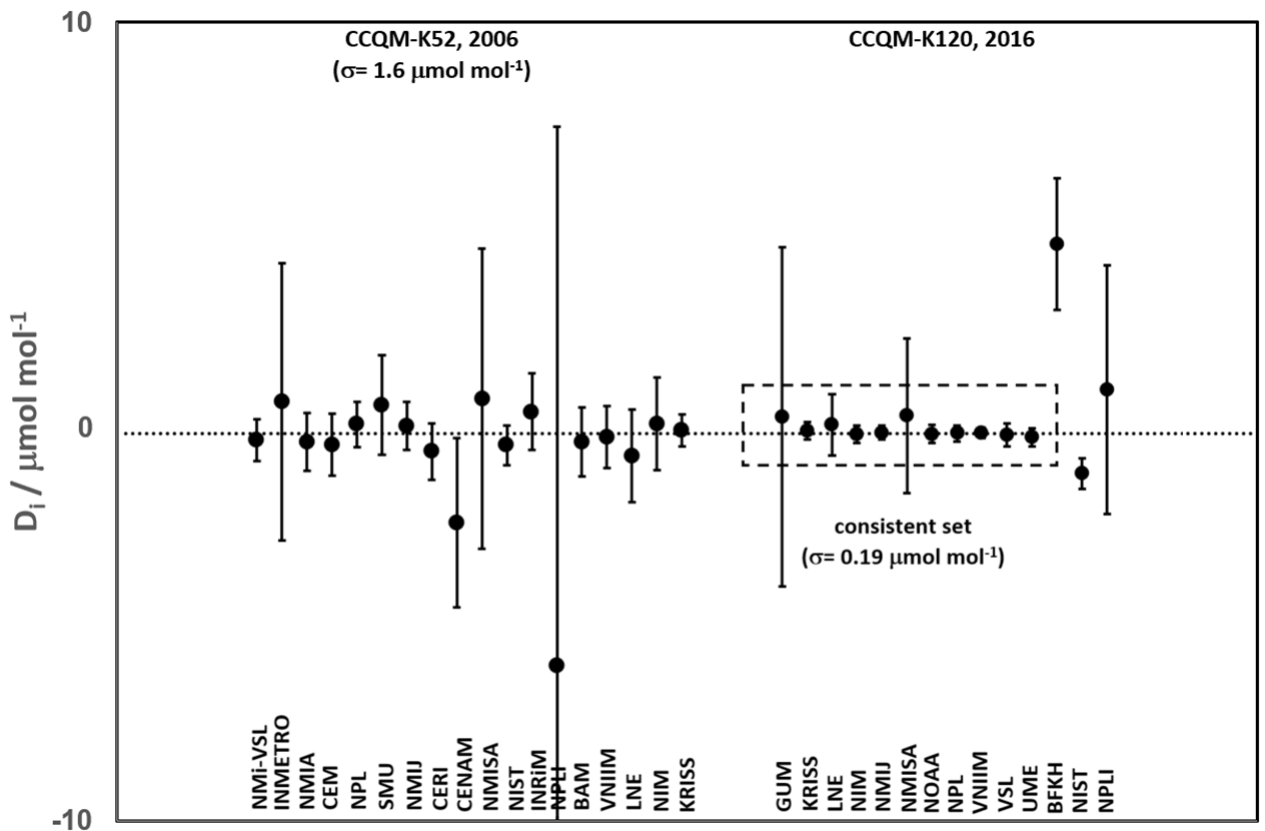

Figure 2. Degree of equivalence between carbon dioxide in air amount fractions (nominal value $380 \mu \mathrm{mol} \mathrm{mol}^{-1}$ ) during the key comparisons CCQM-K52 (2006) and CCQM-K120 (2016). The box indicates participants selected as forming a consistent set of standards. The error bars represent the expanded uncertainty at a $95 \%$ level of confidence.

the reference material is the determination of these in each of the input gases. In recent years, a major focus of the CCQMGAWG has been to reduce the uncertainties of the assigned amount fractions in the primary realisation of composition for key greenhouse gases to align with the data quality objectives (DQOs) of the WMO-GAW programme deemed necessary to enable trends to be identified [30]. The DQOs are qualitative and quantitative statements that clarify the objectives of observations, define the appropriate type of data, and specify tolerable levels of uncertainty. DQOs are used as the basis for establishing the quality and quantity of data needed to support decisions. This has directed research towards achieving standard uncertainties as small as $0.025 \mu \mathrm{mol} \mathrm{mol}^{-1}$ at a nominal amount fraction of $400 \mu \mathrm{mol} \mathrm{mol}{ }^{-1}$ for carbon dioxide in air [20], $0.5 \mathrm{nmol} \mathrm{mol}^{-1}$ at a nominal amount fraction of 1800 nmol mol ${ }^{-1}$ for methane in air [22] and $0.05 \mathrm{nmol} \mathrm{mol}^{-1}$ at a nominal amount fraction of $330 \mathrm{nmol} \mathrm{mol}{ }^{-1}$ for nitrous oxide in air [23], as reported in respective key comparison reports. 
Table 1. Estimated best detection limits (expressed as amount fractions) and measurement techniques for carbon dioxide, methane and nitrous oxide.

\begin{tabular}{ccc}
\hline Component & Measurement technique & $\begin{array}{c}\text { Best detection limit } \\
\left(\mathrm{nmol} \mathrm{mol}^{-1}\right)\end{array}$ \\
\hline $\mathrm{CO}_{2}$ & Gas chromatography (methaniser and flame ionisation detector) & $2.0 \pm 1.0$ \\
& Spectroscopy & $1.0 \pm 0.2$ \\
$\mathrm{CH}_{4}$ & Gas chromatography (flame ionisation detector) & $1.0 \pm 0.5$ \\
& Spectroscopy & $0.2 \pm 0.1$ \\
$\mathrm{~N}_{2} \mathrm{O}$ & Gas chromatography (electron capture detector) & $0.1 \pm 0.1$ \\
& Spectroscopy & $0.02 \pm 0.02$ \\
\hline
\end{tabular}

Expanded uncertainties, at $95 \%$ coverage, of ( 0.13 to 0.20$)$ $\mu \mathrm{mol} \mathrm{mol}{ }^{-1}$ for carbon dioxide, (1.0 to 3.5$) \mathrm{nmol} \mathrm{mol}^{-1}$ for methane and $0.2 \mathrm{nmol} \mathrm{mol}^{-1}$ for nitrous oxide for secondary reference materials (SRMs) have been achieved [8, 31]. Until recently these targets were unprecedented amongst the metrology community.

Gravimetric reference materials for carbon dioxide, methane and nitrous oxide can be prepared in 'synthetic' or 'whole' air. In the case of synthetic air, nominally pure samples of argon, oxygen and nitrogen are mixed in 'atmospheric' proportions. Each one of the gases should be analysed for impurities (particularly the components of interest: argon, oxygen, nitrogen, carbon dioxide, methane and nitrous oxide). Whole air is collected from the atmosphere, preferably at an un-polluted location, dried and compressed into cylinders. It is important that any critical impurities, particularly the target component(s) are removed or reduced to a low level. Any trace impurity of the target component in the matrix gas (synthetic or whole air) should be accounted for in the final gravimetric value assignment, including the uncertainty, of the reference material [26, 29].

When synthetic air is used to prepare gas mixtures, the amount of argon, oxygen and nitrogen should be prepared at ambient levels to accurately match the amount fractions of those components in the whole air [32], this is especially important for use with spectroscopic techniques such as nondispersive infra-red (NDIR), FTIR, tunable diode laser absorption spectroscopy (TDLAS) and cavity ring-down spectroscopy (CRDS). Potential sources of bias have been reported, including matrix composition dependent pressure broadening effects, described for example by Chen et al [33], Rella et al [34], and Nara et al [35], who quantified the bias introduced by deviations in the main component fractions within synthetic air matrices compared to ambient air composition. This is also critical to determine an accurate molecular mass for the whole air, which in turn is used in the calculations to determine the final amount fractions of carbon dioxide, methane and nitrous oxide in the reference material [28].

Improvements in instrumentation for gravimetry and determinations of trace amount fractions of the target component in the matrix air have been reported to result in reductions in combined uncertainties. For example, for methane reference materials, standard uncertainties have been reduced from $0.2 \%$ to $0.033 \%$ relative $[36,37]$. State-of-the-art instrumentation has allowed NMIs to measure these components at trace levels and with small uncertainties as shown in table 1.
The state-of-the-art in preparation of gas reference materials incorporates the use of automated weighing systems [38]. The only operation required of the user is to place the cylinders onto the facility at each weighing stage in the preparation process, which allows more consistent positioning of the cylinder on the balance each time. Automation allows for more measurements than would be achieved with a manual procedure and as a result, measurement precision is enhanced by producing larger data sets in the same time. These systems typically produce mass data with a standard uncertainty of $2 \mathrm{mg}$ from a distribution of ten measurements. Therefore, if sufficient gas either from pure, a diluted mixture, or the balance air, is added to the cylinder then the relative uncertainty in the gravimetric measurement can become almost insignificant. A cylinder is typically evacuated to around $1 \times 10^{-5} \mathrm{~Pa}$ and the average mass of the evacuated cylinder $\left(m_{\mathrm{evac}}\right)$ is measured and subtracted from the mass of the cylinder when the pure gas $\left(m_{\mathrm{p} \text {-gas }}\right)$ has been added. From this the mass of pure gas added $(m)$ is determined. For example, $20 \mathrm{~g}$ of pure gas with a standard uncertainty of $2 \mathrm{mg}$ contributes $0.014 \%$ to the overall relative standard uncertainty $\left(u_{\text {rel }}\right)$ of the mass transferred as calculated from the equation (1)

$$
u_{\mathrm{rel}}=\frac{\sqrt{u_{\mathrm{evac}}^{2}+u_{\mathrm{p}-\mathrm{gas}}^{2}}}{m} .
$$

Therefore, adding ten times more pure gas would result in $u_{\text {rel }}$ of $0.0014 \%$ which is negligible compared to all other sources of error. Adding more pure gas would result in a lower uncertainty, however this would be at the expense of an increasing number of dilution steps required to achieve the ambient levels for the component(s) of interest which would lead to increased uncertainty. Typical gravimetric dilution factors are chosen to be between 10 and 50. Facilities with enclosed automatic weighing systems, also record temperature, humidity and atmospheric pressure of the environment around the system and balance, allowing a correction to be made for any changes in air buoyancy.

Historically, carbon dioxide, methane and nitrous oxide gas reference materials at atmospheric amount fractions have been considered to be stable within the stated uncertainties. However, with recent analytical improvements, the effects of adsorption of the target component to the walls of the cylinder and valve have been demonstrated, as studied further by Leuenberger et al [39]. Within NMIs, 'daughter/ mother' testing (also known as the decant method) was 
introduced to estimate losses due to initial adsorption of the component on the surface [40]. For example, an aliquot from a mixture of nominally $400 \mu \mathrm{mol} \mathrm{mol}{ }^{-1}$ of carbon dioxide in air (mother) is transferred to a clean and evacuated cylinder (daughter). The daughter and mother mixtures are then analysed and a ratio between the two is calculated from the instrument responses. Differences of around 0.2 $\mu \mathrm{mol} \mathrm{mol}{ }^{-1}$ from initial adsorption loss have been reported and shown to be independent of the amount fraction of the parent mixture. [41] In addition, increases in the amount fraction have been observed as the pressure in the cylinder is reduced due to desorption of the carbon dioxide from the walls of the cylinder [42]. Corrections based on the initial adsorption of carbon dioxide are made to the overall gravimetric amount fraction. These effects were considered in the international comparison CCQM-K120 on carbon dioxide [20]. These adsorption/desorption issues have not been observed with methane or nitrous oxide. While these adsorption/desorption effects are still not fully understood or quantified, what is known has helped to increase the accuracy of the reference materials.

\subsection{New activities for isotope ratio}

2.3.1. The growing importance of isotope ratio measurements for accurate gas reference materials. Three major sources of uncertainty for gravimetric preparation of reference materials must be characterised and controlled: mass measurement, gas purity and the relative atomic or molecular masses of the gases being weighed.

The relative atomic masses of the elements are tabulated [43] with uncertainties that, except for the mononuclidic elements, are dominated by the distribution of isotopes seen in naturally occurring elements from different environments. Reducing the uncertainties requires the measurement of isotope ratios in the sample, or by using the information available about the source(s) of the material(s) at hand [28].

Historically, the component of uncertainty that has limited accuracy has been the determination of purity of the gases being weighed, with the potential variation in isotope ratios not considered to significantly affect the amount fraction values and uncertainties achievable. Similarly, gas reference materials have been compared with techniques that were sensitive to the total amount fraction of the component of interest (e.g. GC with flame ionisation detectors (FID) or GC with thermal conductivity detectors (TCD)) and not a particular isotopocule. However, as gas analysers that are based on techniques that are sensitive to variations in isotopocule fractions have become more prevalent, further attention has been paid to the isotopic composition of the component of interest in the reference materials. Spectoscopic techniques used for high-end applications are also sensitive to differences in the composition of the matrix gas, adding a further demand to the basket. This section reviews the impact of isotope ratio variation of gas reference materials on their commutability, and how measurements of isotope ratio are being incorporated into gas reference material production and value assignment procedures to ensure the compatibility.
2.3.2. Comparisons affected by variability in the isotopic composition of the component. One of the first CCQM comparisons, in which gas reference materials were compared under repeatability conditions, CCQM-P23 [44], focused on verifying the uncertainties of gravimetrically prepared gas reference materials (carbon monoxide in nitrogen), by reducing the influence of analytical uncertainties. The comparison included gas mixtures submitted at several amount fractions to one laboratory for analysis under repeatability conditions. At these higher than ambient amount fractions, relative standard uncertainties of the order of $0.01 \%$ were reported and expected to be validated. However, the comparison results demonstrated much larger inconsistencies when the analytical method was NDIR, up to $1 \%$ in some instances. These discrepancies were largely removed if GC-TCD or GC-FID was used as the comparison method. Subsequent measurements of the absolute ${ }^{13} \mathrm{C} /{ }^{12} \mathrm{C}$ ratios of the carbon monoxide in these gas mixtures reported a subset with ratio values grouped around 0.011 , close to natural abundance, but others with measured values of 0.009 and even 0.004 . The sensitivity of NDIR to isotopic composition of carbon monoxide was subsequently studied and reported [45], as well as methods to screen pure carbon monoxide gas to ensure its isotopic composition was close to natural abundance if it was to be used for the manufacture of calibration reference materials. Furthermore, whilst a bias proportional to the difference in isotope ratio from natural abundance could be demonstrated for the NDIR instruments tested, the exact relationship was dependent on the particular analyser. The variation in isotope ratios found in the pure carbon monoxide gases was reported to be due to the source and treatment of the gases, with a number of the gases having been processed to remove ${ }^{13} \mathrm{C}$ carbon monoxide for delivery to the ${ }^{13} \mathrm{C}$ labelled chemical market, leaving the remaining carbon monoxide gas depleted of ${ }^{13} \mathrm{C}$ isotopologues.

\subsubsection{Accurate and commutable reference materials for} carbon dioxide amount fraction measurements. The atmospheric monitoring community has driven the requirement for gas reference materials with reduced measurement uncertainties for monitoring long-term trends of greenhouse gas levels. Global networks [30, 46] for carbon dioxide monitoring within the WMO-GAW programme aspire to keep network biases less than $0.1 \mu \mathrm{mol} \mathrm{mol}{ }^{-1}\left(0.05 \mu \mathrm{mol} \mathrm{mol}{ }^{-1}\right.$ in the southern hemisphere).

The first comparisons of carbon dioxide in air reference materials at atmospheric background amount fractions organised by the CCQM-GAWG, CCQM-P41 [18], occurred in 2003 with a second comparison, CCQM-K52 [21] in 2006. The direct comparison of the gas reference materials (CCQMP41 part 2) was carried out using GC-TCD. This method is insensitive to the isotopic composition of carbon dioxide in the gas reference materials, and the spread of results, which were within a range of $\pm 0.5 \mu \mathrm{mol} \mathrm{mol}{ }^{-1}$ of the reference value (if calculated using methods developed in later comparisons of this type-see CCQM-K82 [22]), were due to other factors. The CCQM-K52 comparison of carbon dioxide in air, at nominally $365 \mu \mathrm{mol} \mathrm{mol}{ }^{-1}$, was performed by all 
nineteen participants measuring reference materials that had been sent to them with reference values that had been assigned with standard uncertainties of $0.2 \mu \mathrm{mol} \mathrm{mol}^{-1}$. The majority of laboratories demonstrated agreement of their measurement capabilities within $\pm 1 \mu \mathrm{mol} \mathrm{mol}{ }^{-1}$. Thirteen participants used GC-TCD or GC-FID analysers for comparison with their in-house reference materials and no isotope effects were observed. For the seven participants using NDIR analysers, no isotopic effects were quantified or reported and measurement uncertainties were large in comparison to the expected size of the effects, apart from two participants (who did report isotope effects or whose uncertainties were not large in comparison). One of the participants, working closely with the atmospheric monitoring community, investigated and published [47] the effect of carbon dioxide isotopic variations on NDIR measurements. A difference approaching $0.2 \mu \mathrm{mol} \mathrm{mol}^{-1}$ was reported for measurements of reference materials with near ambient isotopic composition compared to those with highly depleted isotope ratios made from carbon dioxide from a combustion source.

Commercial laser-based analytical systems, such as TDLAS and CRDS, for trace gases have been developed with sufficient resolution to be able to measure the absorption of single isotopologues of carbon dioxide, which can be used for the measurement of amount fractions. Good agreement between CRDS and NDIR measurements was demonstrated [33] when a number of potential sources of bias were controlled, including the isotopic composition. The correction for isotope effects was shown to lead to the removal of a $0.15 \mu \mathrm{mol} \mathrm{mol}{ }^{-1}$ bias, resulting in the mean difference between the measurement techniques being reduced to $(0.05 \pm 0.09) \mu \mathrm{mol} \mathrm{mol}{ }^{-1}$.

The theoretical bias in amount fraction measurements caused by different isotope ratios in calibrant and sample gases can be readily calculated from measured isotope ratios, expressed in delta notation and traceable to conventional standards. As a first approximation, when carbon dioxide is measured as the major isotopocule ${ }^{12} \mathrm{C}^{16} \mathrm{O}_{2}$, a $1 \%$ o difference in $\delta^{13} \mathrm{C}$ values between the calibration and sample gases leads to a difference of $4 \mathrm{nmol} \mathrm{mol}^{-1}$ in the amount fraction of a $400 \mu \mathrm{mol} \mathrm{mol}{ }^{-1}$ mixture, and $2 \mathrm{nmol} \mathrm{mol}^{-1}$ for the same difference in $\delta^{18} \mathrm{O}$ values. Blending carbon dioxide gases from different sources provides a method for matching to natural abundance isotope ratios for ${ }^{13} \mathrm{C}$, with the mixing of industrially sourced carbon dioxide with highly enriched ${ }^{13} \mathrm{CO}_{2}$ described [48] as well as mixing with pure carbon dioxide obtained from a gas well source [49] $\left(\delta^{13} \mathrm{C}\right.$ at $-1 \%$ o versus Vienna Peedee Belemnite (VPDB)), with $\delta^{18} \mathrm{O}$ values better matched to atmospheric values using the latter source.

The latest comparisons of carbon dioxide in air mixtures CCQM-K120 [20], have focused on demonstrating equivalence of reference materials at better than the $0.1 \mu \mathrm{mol} \mathrm{mol}^{-1}$ level and correcting optical instrument responses for measured isotope ratios of compared carbon dioxide gases. The comparison at the BIPM consisted of forty four gas reference materials, prepared by fourteen participating laboratories. Two measurement techniques were used to compare the reference materials, to ensure no measurement method dependent bias: GC-FID and FTIR spectroscopic analysis. The latter had to be corrected for the isotopic composition of the carbon dioxide gases, involving measurements of isotope ratios in each reference material. The method used by the BIPM for measuring isotope ratios is described in a recent publication [49] and was validated with carbon dioxide in air reference materials that had been value assigned for their isotopic composition by BGC-IsoLab Jena, with traceability of the standards used to the VPDB- $\mathrm{CO}_{2}$ scale realised by the Jena reference air set (JRAS)-06 scale. The isotope ratios of submitted gases were found to range from $-66.9 \%$ to $+0.2 \%$ versus VPDB for $\delta^{13} \mathrm{C}$ and $-34.5 \%$ to $-0.3 \%$ versus VPDB- $\mathrm{CO}_{2}$ for $\delta^{18} \mathrm{O}$. Typical standard uncertainties for the isotope ratio measurements made by laser spectroscopy were $0.2 \%$ and $0.5 \%$ ofor $\delta^{13} \mathrm{C}$ and $\delta^{18} \mathrm{O}$ respectively. Whilst these uncertainties are considerably greater than can be achieved by mass spectrometry, achieving them still requires careful consideration of the calibration strategy and traceability chain, both in terms of strategy [50] and standards to be used [49]. A comparison being coordinated jointly by the BIPM and the IAEA [51] aims to determine the compatibility of isotope ratio measurements of carbon dioxide, both in nominally pure carbon dioxide and carbon dioxide in air reference materials using a variety of analytical techniques.

The CCQM-K120 comparisons were successful in demonstrating the degrees of equivalence of carbon dioxide in air reference materials amongst participating NMIs at nominal amount fractions of $380 \mu \mathrm{mol} \mathrm{mol}{ }^{-1}, 480 \mu \mathrm{mol} \mathrm{mol}^{-1}$ and $800 \mu \mathrm{mol} \mathrm{mol}{ }^{-1}$, with a standard uncertainty of $0.05 \mu \mathrm{mol}$ $\mathrm{mol}^{-1}$ (a reduction by a factor of at least 4 relative to CCQMK52). The methods based on spectroscopy (FTIR, with corrections for isotope ratios) and GC-FID for comparing carbon dioxide in air reference materials demonstrated excellent agreement, with the standard deviation of the difference in reference values found by the two methods being $0.07 \mu \mathrm{mol}$ $\mathrm{mol}^{-1}$ at $380 \mu \mathrm{mol} \mathrm{mol}^{-1}$ and $0.05 \mu \mathrm{mol} \mathrm{mol}^{-1}$ at $480 \mu \mathrm{mol}$ $\mathrm{mol}^{-1}$. It also demonstrated that providing reference materials to communities measuring atmospheric carbon dioxide with spectroscopic methods produced with carbon dioxide originating from combustion sources can lead to isotope ratios in the carbon dioxide which will produce biases in amount fractions measurements of up to $0.3 \mu \mathrm{mol} \mathrm{mol}{ }^{-1}$. These biases can be corrected by either measuring isotope ratios of the gas reference material and appropriate processing by the user, or by using carbon dioxide which has been closely matched to atmospheric isotope ratio values in the production of the reference material. Isotopic differences in the reference materials that define the WMO-CO $\mathrm{CO}_{2}$-X2007 ( $\mathrm{CO}_{2}$-in-air) scale have also been measured [52] and are now accounted for in the propagation of the scale, with isotope ratios reported as characterised to $\pm 0.2 \%$ or for both $\delta^{13} \mathrm{C}$ and $\delta^{18} \mathrm{O}$ values. Absolute ratios for ${ }^{13} \mathrm{C} /{ }^{12} \mathrm{C}$ and ${ }^{18} \mathrm{O} /{ }^{16} \mathrm{O}$ which are currently known with uncertainty at about $1 \%$ o (see below) appear to be another source of uncertainty.

Based on these developments and the advent of optical spectroscopy for measurements of isotope ratio, some NMIs are now focusing on developing appropriate reference materials with isotope ratios traceable to reference materials produced by the IAEA. 


\section{Developments in the WMO-GAW programme}

Within the WMO-GAW programme, the concepts of scale and scale propagation are fundamental to underpinning amounts fractions of carbon dioxide, methane, nitrous oxide and other gases. The concept of scale rests on the idea that measurement precision is usually smaller than the absolute uncertainty of the quantity measured [53]. To achieve a high level of network compatibility (minimal bias between sites), all measurements should be traceable to the same reference which is proven stable over time [30]. Within the WMO-GAW programme, that reference consists of one or more primary gas reference materials, value-assigned using primary methods, or value-assigned by consensus in the case of stable isotopes of carbon dioxide and methane (artefact-based VPDB and Vienna standard mean ocean water (VSMOW) scales) [30]. Primary standards are used to realise a scale over a particular amount fraction or isotopic delta range (see section 3.3). Scales for greenhouse gas amount fractions (excluding stable isotopes) are maintained and propagated by Central Calibration Laboratories (CCLs) [30, 54, 55]. For example, the National Oceanic and Atmospheric Administration (NOAA) acts as the CCL for carbon dioxide, methane and nitrous oxide.

The stable isotope scales have some principal differences. The scales and initial primary standards are based on historical artefacts used for scale-definitions [15]. Primary stable isotope reference materials are maintained by the IAEA and are intended for the highest scale-realisation in practice [15]; there is no primary method linking these scales to SI; preparing materials of desired isotope composition independently of artefact-based reference materials is not possible.

Scale propagation for amount fraction typically follows a hierarchical scheme. The primary standards are used to define an instrument response function, and this is then used to value-assign secondary and tertiary standards. In the case of carbon dioxide, methane and nitrous oxide, secondary standards consist of cylinders containing whole air, or modified whole air with amount fractions spanning the range of interest. Whole air is used rather than synthetic air mixtures to avoid gas matrix effects when propagating the scale to WMO laboratories. Primary standards are analysed periodically to verify secondary assignments, but this is done relatively infrequently (once or twice per year) in order to preserve the primary standards. Scales are distributed by the CCL to other WMO-GAW laboratories through tertiary or quaternary level standards rather than through primary or secondary standards. The CCL for carbon dioxide and methane has improved scale propagation in recent years. Until recently, gas reference materials were value assigned using NDIR for carbon dioxide and GC-FID for methane. Both of these analytical systems were updated with state-of-the-art spectroscopic analysers in 2016. Scale propagation improved by about a factor of three to $0.01 \mu \mathrm{mol} \mathrm{mol}{ }^{-1}$ for carbon dioxide [49], and approximately a factor of five to $0.1 \mathrm{nmol} \mathrm{mol}^{-1}$ for methane. A similar upgrade is planned for nitrous oxide.

For stable isotopes of carbon dioxide in air, the VPDB scale is propagated by distribution of carbon dioxide in air standards, known as JRAS flasks or by user-supplied tanks calibrated by the Stable Isotope Laboratory of the Max-Planck-Institute for Biogeochemistry (BGC-IsoLab), the CCL for carbon dioxide stable isotopes [30]. The carbon dioxide in JRAS mixtures is derived from carbonates and traceable to the internationally accepted VPDB scale through a chain of analyses against primary reference material(s) (see section 3.3).

Also fundamental to the WMO-GAW programme for greenhouse gases is the concept that scales are well-defined scales. Scale realisations are typically identified by the year in which they are adopted (e.g. WMO- $\mathrm{CO}_{2}-\mathrm{X} 2007$ ) and are updated as needed, such as when primary standards are added or removed from the set [56], or when advances in analytical methods reveal previously unknown deficiencies. Sometimes a scale revision is necessary due to propagation issues but is still based on the same set of primary standards. The revisions are still uniquely identified by name. An example of this is the WMO nitrous oxide scale. WMO- $\mathrm{N}_{2} \mathrm{O}-\mathrm{X} 2006$, was realised in 2006 [57] and at that time secondary standards were assigned relative to the primaries. Several years later it was discovered that one of the secondary standards was drifting at $\sim-0.05 \mathrm{nmol} \mathrm{mol}^{-1} \mathrm{a}^{-1}$. This impacted reference gas assignments made by the CCL from January 2006 to October 2011, and required re-assignment of nitrous oxide values of the secondary standards and retroactive propagation through the calibration hierarchy. This re-assignment was identified as a new scale, WMO-N $2 \mathrm{O}-\mathrm{X} 2006 \mathrm{~A}$.

\subsection{State of the art in underpinning measurements of amount fraction}

Two primary methods, gravimetry and manometry, are used to provide primary reference materials for WMO-GAW measurements of carbon dioxide, methane and nitrous oxide. Here we provide brief histories of these methods as they apply to WMO-GAW along with some recent advances.

3.1.1. Gravimetry. Primary standards for methane and nitrous oxide are prepared using analytical balances, mass comparators, and gas blending manifolds as described in ISO 6142-1 [26]. In general, a known mass of the minor component is added to an evacuated cylinder and diluted with a known mass of the major component. The mass of the minor component can be determined in various ways: (a) by direct transfer of an aliquot to an evacuated cylinder followed by weighing, or (b) by adding a small amount of gas to a small transfer vessel $\left(5-50 \mathrm{~cm}^{3}\right)$, weighing, and then transferring the aliquot to an evacuated cylinder. Transfer from a vessel can involve expansion from the transfer vessel into the target, or expansion plus flushing [56] in which the vessel is repeatedly pressurised and the contents expanded into the cylinder. For methane, all three methods were used to create a suite of primary standards (direct addition, expansion, expansion with flushing). For nitrous oxide, only the expansion with flushing method was used [57]. An advantage of direct addition is that it ensures complete transfer because the mass of the aliquot is determined after it has been added to the cylinder. An advantage of the transfer vessel method is that relatively large dilution 
Table 2. Primary standards used to define WMO scales for carbon dioxide, methane and nitrous oxide.

\begin{tabular}{lllll}
\hline Component & $\begin{array}{l}\text { No. of primary } \\
\text { standards }\end{array}$ & Method & Nominal amount fraction range & Scale ID \\
\hline $\mathrm{CO}_{2}$ & 15 & Manometry & $(250-520) \mu \mathrm{mol} \mathrm{mol}^{-1}$ & ${\mathrm{WMO}-\mathrm{CO}_{2}-\mathrm{X} 2007}^{-1}$ \\
$\mathrm{CH}_{4}$ & 22 & Gravimetry & $(300-5900) \mathrm{nmol} \mathrm{mol}^{-1}$ & $\mathrm{WMO}-\mathrm{CH}_{4}-\mathrm{X} 2014 \mathrm{~A}$ \\
$\mathrm{~N}_{2} \mathrm{O}$ & 13 & Gravimetry & $(260-370) \mu \mathrm{mol} \mathrm{mol}^{-1}$ & ${\mathrm{WMO}-\mathrm{N}_{2} \mathrm{O}-\mathrm{X} 20006 \mathrm{~A}}$ \\
\hline
\end{tabular}

factors can be achieved (up to $2 \times 10^{5}$ in a single step). A disadvantage of the transfer vessel method is that it requires quantitative knowledge of the transfer efficiency. High transfer efficiencies can be achieved with care [58].

For both methane and nitrous oxide, primary standards were prepared gravimetrically in 5.91 aluminium cylinders. For methane seventeen standards were prepared from 1991-1995 over the nominal range (300-2600) nmol mol ${ }^{-1}$ [56] with additional standards prepared in 2013 to verify the original work and extend the range to $5900 \mathrm{nmol} \mathrm{mol}^{-1}$ (table 2). Scrubbed whole air (i.e. whole air from which methane, carbon dioxide, and nitrous oxide is removed to produce residual levels of $<10 \mathrm{nmol} \mathrm{mol}^{-1},<100 \mathrm{nmol} \mathrm{mol}^{-1}$ and $<5 \mathrm{nmol} \mathrm{mol}^{-1}$ respectively) was used as the dilution gas. Uncertainties were limited to some extent by difficulties in determining the amount of methane in the dilution gas (often a few nmol mol ${ }^{-1}$ ) $[24,56]$.

For nitrous oxide fifteen standards over the nominal range 260-370 nmol mol ${ }^{-1}$ were made gravimetrically from four parent mixtures at higher amount fractions [57, 59]. Synthetic air (oxygen and nitrogen) was used as dilution gas because scrubbed whole air often contains trace amounts of nitrous oxide, which can be difficult to quantify. This constrains the use of the current WMO-GAW primary standards as they cannot be used to calibrate spectroscopic instruments directly because they lack argon, which could be important with respect to pressure broadening [60]. Scale transfer is currently achieved using gas chromatography with electron capture detection (GC-ECD). Work is underway to prepared nitrous oxide standards in scrubbed whole air.

The sets of primary standards for nitrous oxide and methane show good internal consistency. The standard deviation of residuals from a 2 nd order polynomial fit to twenty two methane standards, based on GC-FID analysis, is $3.4 \mathrm{nmol}$ $\mathrm{mol}^{-1}$. For nitrous oxide, the standard deviation of residuals is $0.33 \mathrm{nmol} \mathrm{mol}^{-1}$ [57] based on GC-ECD analysis. In addition to CCQM comparisons, WMO-GAW scales have also been compared with other independent scales, such as those from the Scripps Institution of Oceanography (SIO) and Tohoku University (TU) [61]. Through comparison of more than twenty years of atmospheric measurements at multiple sites, a divergence between the SIO scale 'SIO-98' and the WMO scale 'WMO- $\mathrm{N}_{2} \mathrm{O}-\mathrm{X} 2006 \mathrm{~A}$ ' has been observed. A recent update of the SIO scale (now SIO-16) has improved the comparison, but small differences remain [62]. This underscores the need for repeated comparisons.

3.1.2. Manometry. The manometric determination of carbon dioxide in air involves loading a sample of dry whole air into a known volume ('large volume') where its temperature and pressure are determined. Carbon dioxide is then cryogenically extracted from that air sample, cryogenically purified to remove (residual) water vapour, and transferred into a much smaller volume ('small volume'). After reaching thermal equilibrium, the temperature and pressure of the purified carbon dioxide in the small volume are determined. The volumes of the large and small volumes need not be known exactly, but their ratio must be well-known. The amount fraction of carbon dioxide in dry air is derived from ratios of temperature, pressure, and volume, with appropriate corrections for nonideality [63]. Since nitrous oxide cannot be separated from carbon dioxide cryogenically, a correction must be made for the amount of nitrous oxide and its non-ideality.

Manometry has been used to prepare standards for carbon dioxide measurements since C D Keeling began measuring carbon dioxide in background (remote) air at the South Pole in 1957, and at Mauna Loa, Hawaii in March 1958, for Scripps Institution of Oceanography (SIO) [64]. SIO data are traceable to carbon dioxide primary standards value-assigned using either a constant-volume mercury-column manometer (CMM) or an electronic constant-volume manometer (ECM) [65-68].

The CMM used at SIO had a large volume of $5014 \mathrm{~cm}^{3}$ and a small volume of $3.80 \mathrm{~cm}^{3}$ [69]. Pressure was measured by comparing the height of mercury in a column containing the sample to the height of mercury in a vacuum column. Temperatures were determined using mercury thermometers. Cathetometers were used to read the mercury column heights and temperatures through windows in a temperature-controlled housing. The volume ratio was determined by directly weighing the main volumes filled with water or mercury, and by measuring pressure and temperature after expanding gas (carbon dioxide, argon or nitrogen) from the small volume into successively larger volumes [67].

The SIO carbon dioxide amount fraction scale, as determined from CMM measurements of a series of primary standards, was used by the WMO Background Air Pollution Monitoring Network, a predecessor to the GAW programme, as the world reference for carbon dioxide from 1975-1995. Primary standards were measured using the CMM approximately every two years. Results of the CMM measurements were documented in technical reports (e.g. [70, 71]). In 1995, NOAA assumed the role of CCL and established manometric capabilities. The NOAA manometer was modelled on the Scripps CMM, but with electronic devices for pressure and temperature measurement $[63,72]$. NOAA prepared a suite of 15 primary standards, which were initially valueassigned based on both the SIO CMM and the NOAA ECM from 1995-2001. In 2001, NOAA derived an independent scale based solely on NOAA measurements [72]. Similarly to SIO, NOAA analyses primary standards using their ECM 


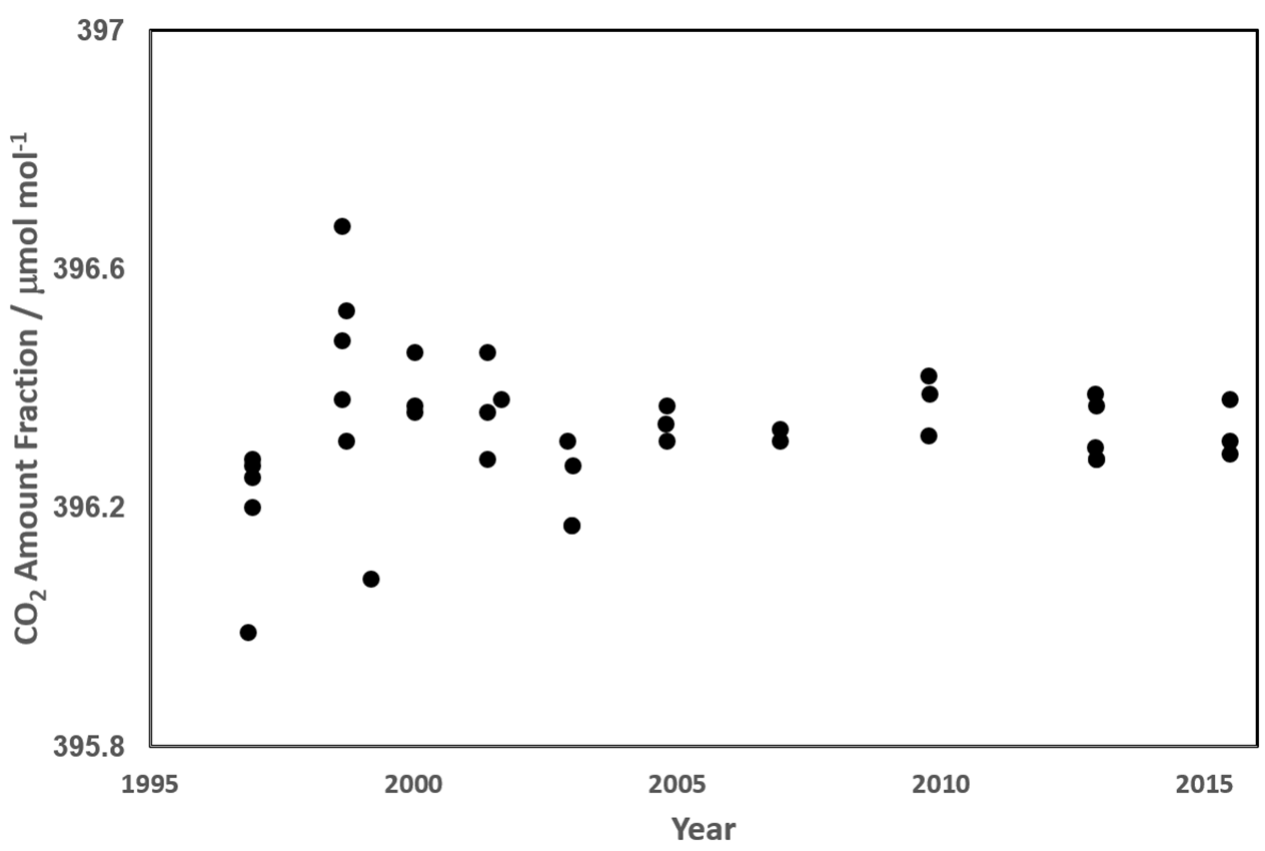

Figure 3. Results from one NOAA primary standard at $400 \mu \mathrm{mol} \mathrm{mol}{ }^{-1}$, showing 10 calibration episodes. Consistency between episodes has improved over time. Here, the standard deviation of all measurement results is $0.1 \mu \mathrm{mol} \mathrm{mol}^{-1}$ but improves to $0.04 \mu \mathrm{mol} \mathrm{mol}^{-1}$ from 2004-2015.

approximately every two years. The current WMO-GAW scale (WMO- $\mathrm{CO}_{2}-\mathrm{X} 2007$ ) is based on NOAA manometric results from 1996 through 2007. NOAA has continued to measure primary standards every two years and has presented updated manometric results at WMO-GAW meetings [73, 74].

Repeatability (estimated as the standard deviation) of CMM and ECM instruments is about $0.018 \%(0.07 \mu \mathrm{mol}$ $\mathrm{mol}^{-1}$ at $\sim 400 \mu \mathrm{mol} \mathrm{mol}^{-1}$ ) $[69,72]$ and has improved over time (figure 3).

Historically, several issues complicated the long-term maintenance of carbon dioxide scales using CMM and ECM. Carbon dioxide 'drift' in cylinders is of primary concern, and can be at the limit of what can be detected over even a decade, given the typical expanded uncertainty associated with the technique $(\sim 0.05 \%)$. Changes in manometer-assigned values over time could be the result of cylinder drift, or changes in the manometer. This dilemma confounded SIO to the point that two separate scales were derived in 1999: one in which cylinders were assumed to be stable and any observed drift attributed to changes in the volume ratio (SIO scale X99A), and one in which the manometer was assumed to be stable and the cylinders thought to be drifting (SIO scale X99B) [69]. This issue was likely complicated by the fact that some of the early SIO primary standards were prepared in steel cylinders, which tend to show higher drift rates than aluminium cylinders [39]. Nevertheless, drift in the amount fraction is not easily resolved. Keeling et al [69] investigated multiple issues related to drift, and concluded that their small volume did not change between 1985 and 2016, but their thermometers drifted $0.11{ }^{\circ} \mathrm{C}$ between 1961 and 2006, and that some of the auxiliary volumes (used to determine the volume ratio) changed over time as they were annealed and 'ashed' each year to remove grease. A revised SIO scale is under development and will incorporate these latest findings.

Interactions of carbon dioxide with manometer surfaces also complicate interpretation of manometer results. SIO has documented small changes in their CMM results following cleaning to remove grease and residual mercury and NOAA is investigating the possibility that carbon dioxide adsorbs to or permeates O-rings. Despite these issues, both SIO and NOAA have maintained carbon dioxide scales that have remained remarkably stable, and in close agreement, for many years [69, 72].

BIPM has developed an all SilcoNert ${ }^{\circledR}$ treated stainless steel ECM with metallic, instead of elastomer, O-rings in all valves to address the interaction of carbon dioxide with glass and other surfaces. Preliminary results show good agreement between this system and the all-glass NOAA system.

3.1.3. Quality assurance and quality control. To address scientific needs for interpreting atmospheric observations of the major greenhouse gases, the GAW programme sets ambitious network compatibility goals, which are reviewed and, if necessary, revised during biennial meetings of the WMOGAW community. Network compatibility goals are defined for the unpolluted troposphere and represent the maximum bias that can generally be tolerated in measurements of wellmixed air used in global models to infer fluxes. Extended network compatibility goals are provided as a guideline for many other studies in which the smallest bias tolerance is not required [30]. These network compatibility goals currently stand at $\pm 0.05 \mathrm{mmol} \mathrm{mol}^{-1}$ for carbon dioxide in the Southern Hemisphere, relaxed to $\pm 0.1 \mu \mathrm{mol} \mathrm{mol}{ }^{-1}$ elsewhere, $\pm 2 \mathrm{nmol}$ $\mathrm{mol}^{-1}$ for methane, and $\pm 0.1 \mathrm{nmol} \mathrm{mol}{ }^{-1}$ for nitrous oxide. The extended goals are set to $\pm 0.2 \mu \mathrm{mol} \mathrm{mol}{ }^{-1}$ for carbon 

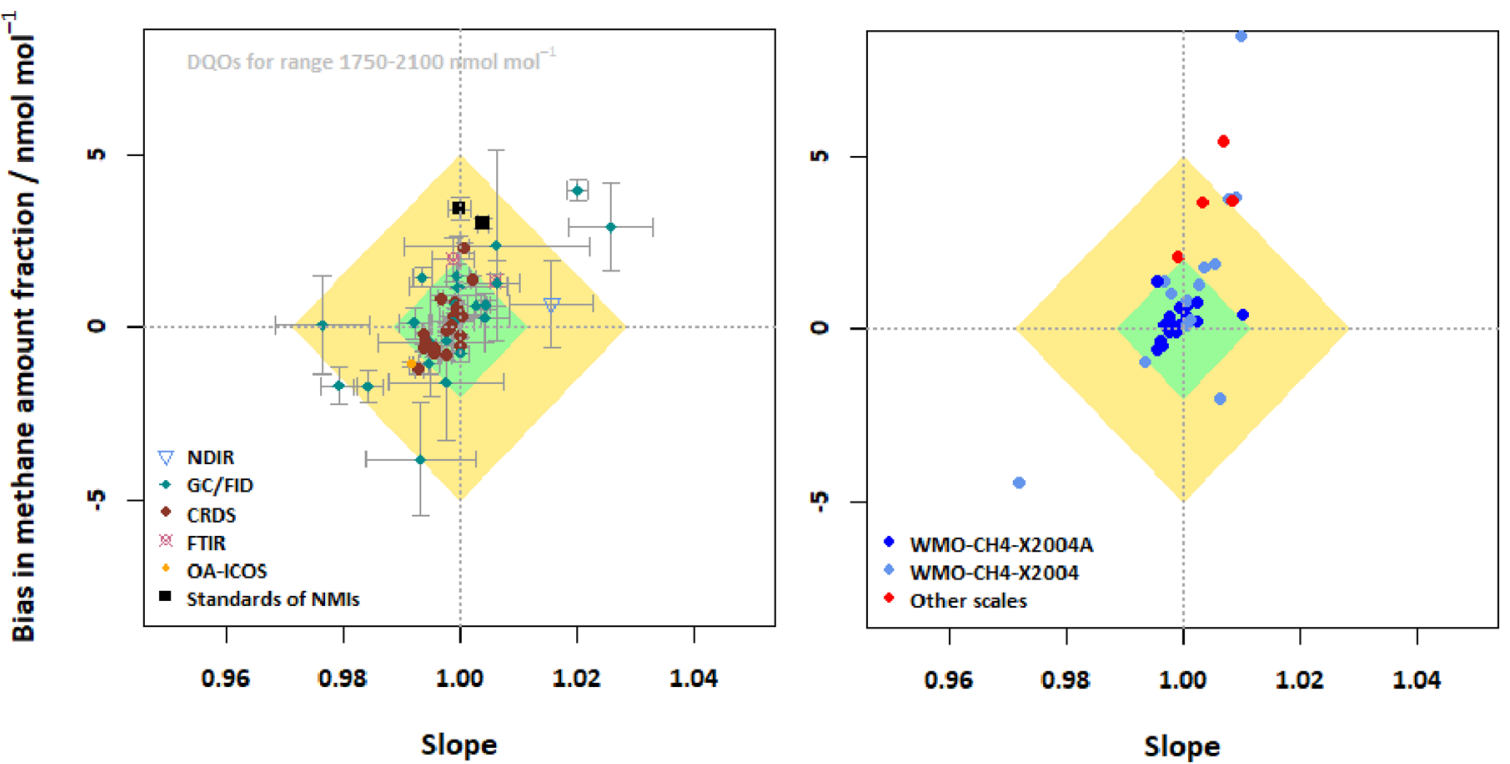

Figure 4. (Left) Analysis of WCC results. Methane bias versus the slope of the audit for individual travelling standard comparisons. Different symbols and colours indicate different measurement techniques of the station analysers. The error bars correspond to the uncertainty of the slope and the bias $(1 \sigma)$. The green and yellow areas correspond to the WMO/GAW compatibility and extended compatibility goals for the relevant amount fraction range. (Right) Analysis of the WMO Round Robin (RR6) results. Different colours refer to the calibration scales used by the participating laboratory.

dioxide, $\pm 5 \mathrm{nmol} \mathrm{mol}^{-1}$ for methane, and $0.3 \mathrm{nmol} \mathrm{mol}^{-1}$ for nitrous oxide.

The WMO-GAW programme has implemented a quality management framework (QMF) to ensure consistent scales and comparability, in the recognition that 'collecting adequate information on the chemical composition of the atmosphere and on the consequences of the anthropogenic impact on different spatial and temporal scales is valuable and possible only if all the relevant measurements are expressed in the same units and on the same scale and if data from different countries and from different sites are comparable' [75]. Further details on the WMO/GAW QMF can be found in the WMO GAW Implementation Plan: 2016-2023 [75]. Briefly, the QMF requires CCLs maintain and enable access to the primary network standards and calibration scales. CCLs are encouraged to compare the WMO-GAW scales to other independent scales whenever possible, e.g. through participation in key comparisons organised by BIPM [22, 23] and other exercises as appropriate. All WMO measurements are made traceable to an appropriate scale [30, 53], which leads to high internal consistency of data within and between networks. World Calibration Centres (WCCs) organise comparison campaigns and performance audits at GAW sites using transfer standards as an independent check of the traceability to the CCL. World Data Centres (WDCs) provide archiving facilities, perform plausibility and consistency checks on submitted data, and provide feedback to the data providers when necessary. QA/QC related issues are further coordinated by Scientific Advisory Groups (SAGs) and Quality Assurance/Scientific Activity Centres (QA/ SACs).

Zellweger et al [76] published results of performance audits made by the WCC for methane (2005-2014) and carbon dioxide (2010-2015) that showed newer spectroscopic techniques such as CRDS have clear advantages in stability and linearity of the response compared to traditional methods. Figure 4 shows an update of the analysis made by Zellweger et al [76] including audit data until 2018 for methane. Briefly, the bias in the centre of the relevant amount fraction of the unpolluted troposphere versus the slope of the linear regression analysis of the standard comparison is shown, which results in allowed bias/slope combinations meeting the WMO-GAW network compatibility (green area) and extended network compatibility goals (yellow area) for the relevant amount fraction. Figure 4 also shows comparisons made between the WCC and standards prepared by NMIs. The NMI standards showed an offset of about 2-3 nmol mol ${ }^{-1}$ compared to the $\mathrm{WMO}-\mathrm{CH}_{4}-\mathrm{X} 2004 \mathrm{~A}$ calibration scale, which is in good agreement with the results of the BIPM key comparison CCQM-K82 [22].

The results obtained during the WCC station performance audits are similar to those from recent WMO/IAEA Round Robin Comparison Experiment (RR6) organised and coordinated by the CCL for methane hosted by NOAA. RR6 took place in 2014/15 with 35 participating laboratories, and involved two methane standards, one containing (average $1756.2 \mathrm{nmol} \mathrm{mol}^{-1}$ ) and the other containing (average 1943.1 nmol $\mathrm{mol}^{-1}$ ) amount fraction [77]. With this data set, the analysis described above was repeated after exclusion of one laboratory, which was far outside the compatibility goal. This excluded laboratory was also audited by the WCC in 2012 and the results were excluded because the instrument was found to be unsuitable for methane analysis. The results of RR6 are also presented in figure 4 (right panel). The percentage of laboratories fulfilling the WMO network compatibility and extended network compatibility goal during WMO RR6 was similar to the results from the WCC station performance audits. The laboratories reporting data on scales other than 

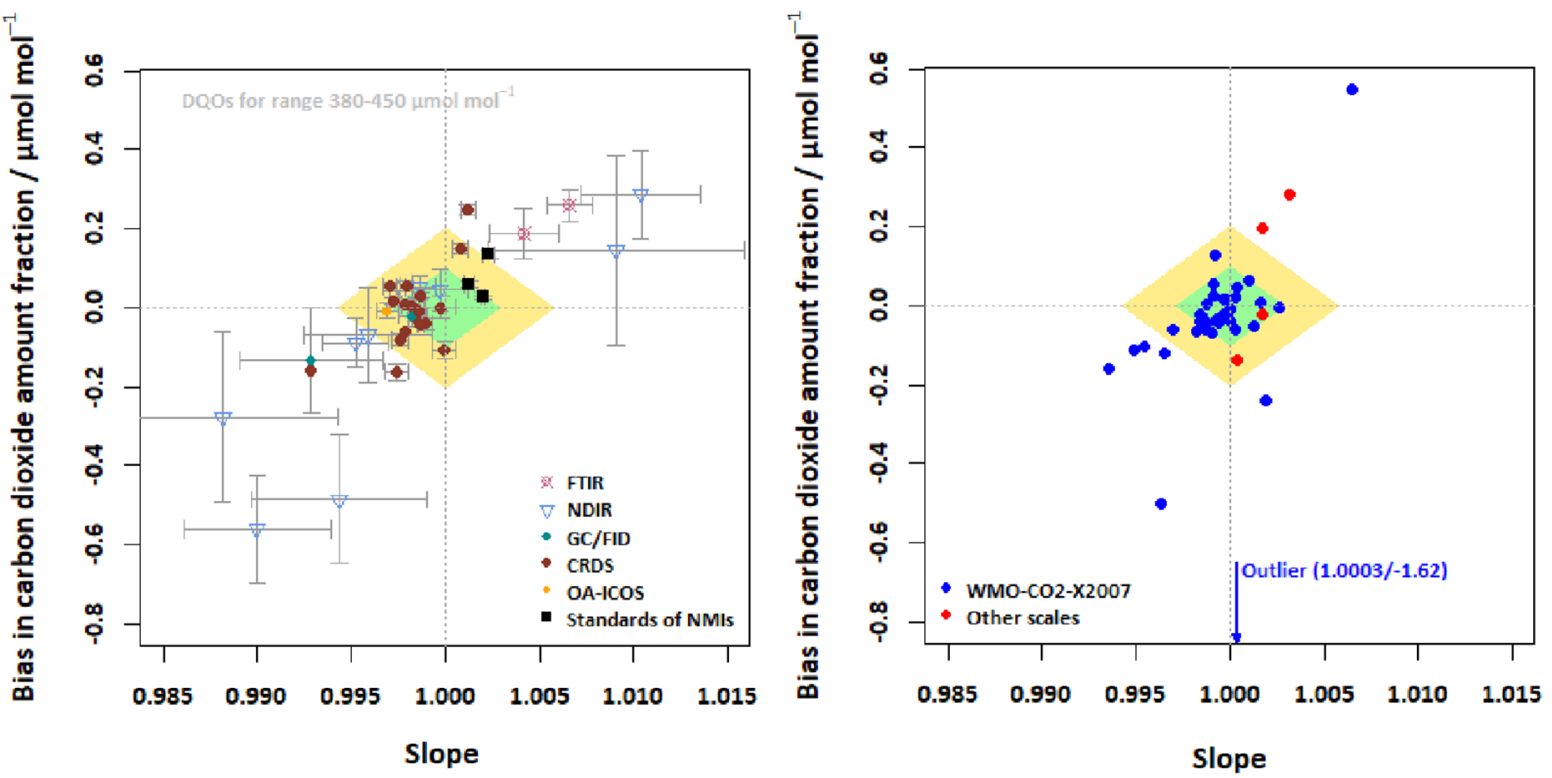

Figure 5. (Left) Analysis of WCC results. Carbon dioxide bias versus the slope of the audit for individual travelling standard comparisons. Different symbols and colours indicate different measurement techniques of the station analysers. The error bars correspond to the uncertainty of the slope and the bias $(1 \sigma)$. The green and yellow areas correspond to the WMO/GAW compatibility and extended compatibility goals for the relevant amount fraction range. (Right) Analysis of the WMO Round Robin (RR6) results. Different colours refer to the calibration scales used by the participating laboratory.

WMO- $\mathrm{CH}_{4}-\mathrm{X} 2004$ and WMO- $\mathrm{CH}_{4}$-X2004A were Japanese labs that used their own gravimetric calibration scales.

Currently, QA/QC is still not systemised for measurements of stable isotopes; there is no WCC identified and there have been no performance audits performed. These shortcomings need to be addressed [30]. The work performed at the CCL aimed at the practical scale-realisation by JRAS mixtures should be independently verified by another laboratory [30]. This is crucial as the stable isotope scales are artefact-based and there is no primary method in use to verify absence of drifts and/or unrecognised biases. Round-robin inter-comparisons, the only QA tool currently in use, demonstrate lab-tolab discrepancies in $\delta^{13} \mathrm{C}$ and $\delta^{18} \mathrm{O}$ on air- $\mathrm{CO}_{2}$ which largely exceed the WMO network compatibility goals [30, 55]. These discrepancies, mainly offsets, in RR6 appear to be largely driven by the fact that most laboratories are not yet on the CCL realisation of the VPDB scale and several improvements have been proposed at GGMT-2017 for RR7 [30].

Figure 5 shows an update of the analysis made by Zellweger et al [76] including audit data until 2018 for carbon dioxide. The same analysis as above was made and also applied to the RR6 results. Again, the addition of new performance audit data confirms the advantage of the CRDS/off-axis integrated cavity output spectroscopy (OA-ICOS) techniques compared to NDIR. Figure 5 also shows comparisons with NMIs and Japanese laboratories reporting on their own calibration scales. Compared to the methane study, the proportion of laboratories complying with the WMO network compatibility goal was smaller for the audits by the WCC, which indicates that the transfer of the calibration to the actual field measurement is more challenging for carbon dioxide. However, this significantly improves if only audits of CRDS instruments are considered.

\subsection{State of the art in underpinning isotope ratio measurement}

The isotopic composition of a sample is generally reported in terms of isotope delta ' $\delta$ ', which is the relative differences of the isotope ratio of a sample to a scale-defining standard, i.e. an artefact accepted by consensus. This is expressed in equation (2)

$$
\delta^{i / j} E=\frac{{ }_{E}^{i / j} R_{\mathrm{S}}-{ }_{E}^{i / j} R_{\mathrm{Ref}}}{{ }_{E}^{i / j} R_{\mathrm{Ref}}}
$$

where $(i)$ denotes the higher and $(j)$ the lower atomic mass of Element $E$ and $R=N(i E) / N(j E)$ is the isotope ratio of the sample $(S)$ or the reference standard [78]. Over the last 60 years a simplified version of equation (2) has asserted itself in the literature (at least regarding the light stable isotopes carbon, hydrogen, oxygen and nitrogen), where the lower atomic mass $(j)$ of an element is omitted [79]. $\delta$ values are typically small and are usually multiplied by 1000 and expressed as 'per mil' $(\% o)$.

3.2.1. Artefact based stable isotope scales (for $\delta^{13} \mathrm{C}, \delta^{18} \mathrm{O}$, $\left.\delta^{2} H, \delta^{15} \mathrm{~N}\right)$ and developments at the IAEA. In the 1960s the IAEA established tritium and stable isotope measurements of water in precipitation that required the development of specific stable isotope reference materials. In particular, this programme required the development of both the scale-defining reference materials and high-level reference materials aimed at scale realisation for stable isotope measurements of hydrogen, carbon, nitrogen, oxygen and sulphur. As custodian for these stable isotope scales, the IAEA maintains the stable isotope scales, monitors and introduces replacement primary 
Table 3. Accepted scale-defining materials, primary reference materials and second scale anchors.

\begin{tabular}{|c|c|c|c|c|c|c|c|}
\hline $\begin{array}{l}\text { Delta } \\
\text { value }\end{array}$ & $\begin{array}{l}\text { Isotope } \\
\text { ratio }\end{array}$ & Scale & $\begin{array}{l}\text { Scale } \\
\text { definining } \\
\text { reference } \\
\text { material }\end{array}$ & Primary reference material & Consensus value & $\begin{array}{l}\text { Second scale } \\
\text { anchor }\end{array}$ & Consensus value \\
\hline \multirow[t]{2}{*}{$\delta^{13} \mathrm{C}$} & ${ }^{13} \mathrm{C} /{ }^{12} \mathrm{C}$ & VPDB & $\begin{array}{l}\text { NBS19 } \\
(\text { marble })^{\mathrm{a}}\end{array}$ & Previously NBS19 (marble) & $1.95 \%$ exactly & $\begin{array}{l}\text { Previously } \\
\text { LSVEC (lithium } \\
\text { carbonate) }^{\mathrm{b}}\end{array}$ & $-46.6 \%$ exactly \\
\hline & & & & Currently IAEA-603 (marble) & $2.46 \% \circ \pm 0.01 \% \circ$ & None $^{c}$ & \\
\hline \multirow[t]{4}{*}{$\delta^{18} \mathrm{O}$} & ${ }^{18} \mathrm{O} /{ }^{16} \mathrm{O}$ & VPDB, & NBS19 & Previously NBS19 (marble) & $-2.20 \%$ exactly & None & - \\
\hline & & VPDB-CO ${ }_{2}$ & $(\text { marble })^{\mathrm{a}}$ & Currently IAEA-603 (marble) & $-2.37 \% \circ \pm 0.04 \% \circ$ & None & - \\
\hline & & VSMOW & VSMOW & Previously VSMOW (water) & $0 \%$ exactly & VSMOW (water) & $-55.5 \%$ exactly \\
\hline & & & (water) & Currently VSMOW2 (water) & $0.00 \% \circ \pm 0.02 \% \circ$ & VSMOW2 (water) & $-55.5 \% \circ \pm 0.02 \%$ \\
\hline \multirow[t]{2}{*}{$\delta^{2} \mathrm{H}$} & ${ }^{2} \mathrm{H} /{ }^{1} \mathrm{H}$ & VSMOW & $\begin{array}{l}\text { VSMOW } \\
\text { (water) }\end{array}$ & Previously VSMOW (water) & $0 \%$ exactly & $\begin{array}{l}\text { Previously } \\
\text { VSMOW (water) }\end{array}$ & $-428 \%$ exactly \\
\hline & & & & Currently VSMOW2 (water) & $0.00 \% \circ \pm 0.3 \% \circ$ & $\begin{array}{l}\text { currently } \\
\text { VSMOW2 (water) }\end{array}$ & $-427.5 \% \circ \pm 0.3 \%$ \\
\hline$\delta^{15} \mathrm{~N}$ & ${ }^{15} \mathrm{~N} /{ }^{14} \mathrm{~N}$ & $\mathrm{~N}_{2}$-air & $\mathrm{N}_{2}$-air & $\begin{array}{l}\text { IAEA-N-1 (ammonium } \\
\text { sulfate) }\end{array}$ & $0.43 \% \circ \pm 0.07 \% \circ$ & $\begin{array}{l}\text { USGS32 } \\
\text { (potassium nitrate) }\end{array}$ & $180 \%$ \\
\hline
\end{tabular}

a Exhausted.

${ }^{\mathrm{b}}$ Discontinued [88].

${ }^{\mathrm{c}}$ Use of other available reference materials instead of LSVEC is recommended [88].

reference materials, and develops new reference materials to address critical applications [15].

Currently, all stable isotope scales for $\delta^{13} \mathrm{C}, \delta^{18} \mathrm{O}, \delta^{2} \mathrm{H}$ and $\delta^{15} \mathrm{~N}$ are based on artefacts, i.e. the ratio of isotopic species in the artefact used to define the scale-zero and where possible a scale span. These historical artefacts (or their later replacements) have also been used for the highest-level scalerealisation. With the exception of the $\delta^{15} \mathrm{~N}_{\text {AIR }}$ scale, these are now exhausted for distribution. The scale defining materials include VSMOW, NBS19 and Air- $\mathrm{N}_{2}$ (see table 3), and in contrast to greenhouse gas amount fraction scales, these scales are not based on an SI-traceable method, i.e. a mixture of isotopic entities $\left({ }^{13} \mathrm{C}\right.$ and $\left.{ }^{12} \mathrm{C}\right)$ with a desired isotope ratio. Nevertheless, best current measurements of the absolute ratios of scale defining primary standards exist and are the basis of calculating atomic weights of natural materials [80]. The exhausted scale-zero defining materials SMOW and PDB were first replaced by VSMOW and NBS19 (NBS19 defines ${ }^{13} \mathrm{C}$ and $\delta^{18} \mathrm{O}$ values close to the scale zero) [84] and later have been replaced by VSMOW2 and IAEA-603 [15, 81, 82] with the value assignment based on measurements against the VSMOW and NBS19 materials. The first replacements are reflected in adding $\mathrm{V}$ (Vienna) to the scale abbreviations. IAEA-N-1 is the primary reference material for the $\mathrm{N}_{2}$-Air scale [78].

The replacements, VSMOW2 and IAEA-603 were introduced to guarantee the consistency of the scale realisation. VSMOW2 was prepared at the IAEA by careful mixing of waters and is identical to VSMOW, within the uncertainties [83]. In contrast, marble carbonates of the desired isotopic composition cannot be prepared, so the isotopic composition of IAEA-603 [82] differs from that of NBS19.

All stable isotope ratio measurement instruments have been shown to suffer from some systematic effects (e.g. memory, cross-contamination, linearity, interference, sample gas preparation steps etc) that can influence the correctness of measurement results and require harmonised calibrations (see section 4). Therefore, in addition to the primary reference material a second scale 'anchor' (with its value assigned based on measurements against primary reference material under optimal conditions) is needed to synchronise the calibration scale span and to be used for data normalisation.

Standard light antarctic precipitation (SLAP), the second scale anchor accepted on the VSMOW scale $\left(\delta^{2} \mathrm{H}=-428 \%\right.$ o and $\delta^{18} \mathrm{O}=-55.50 \%$, values assigned without uncertainty [84]) was developed and later replaced by SLAP2 $\left(\delta^{2} \mathrm{H}=-427.5 \% \circ \pm 0.3 \%\right.$ and $\delta^{18} \mathrm{O}=-55.50 \% \circ \pm 0.02 \% \circ$ as assigned by measurements against SLAP [81]). The replacement SLAP2 was prepared at the IAEA by careful mixing of waters and is almost identical to SLAP (with $0.5 \%$ o difference in $\delta^{2} \mathrm{H}$ for SLAP2) [83].

LSVEC (lithium carbonate) was introduced as the second anchor on the VPDB $\delta^{13} \mathrm{C}$ scale, with a value of $-46.6 \%$ o accepted without uncertainty [85]. Later, LSVEC values were found to be drifting $[86,87]$ so IUPAC has recommended that LSVEC be discontinued as a reference material for $\delta^{13} \mathrm{C}$ data normalisation; other valid reference materials are suggested to be used for this purpose until a replacement for LSVEC is found [88]. However, values for these reference materials were assigned using LSVEC as a scale anchor so when the LSVEC replacement material is released the values of all standards that were standardised with LSVEC may need to be revised. Currently there are efforts underway to make a replacement available to the isotopic community as soon as possible.

All available stable isotope reference materials are based on and are traceable to the historical artefacts. The hierarchy of reference materials (traceability chain) is described below and as the chain is descended, the uncertainty of the reference material increases. 
- Historical artefacts are used to define the scales and as a concept, each scale-defining material has its value assigned with zero uncertainty. In most cases, these artefacts are no longer accessible [78].

- Primary reference materials which either are, or have the closest link to, the historical artefacts. These primary reference materials are used to realise their respective scales, e.g. VSMOW and NBS19 and their replacements VSMOW2 and IAEA-603 (table 3). Like other reference materials, they have an uncertainty (at least due to homogeneity) and this is well characterised for VSMOW2 and IAEA-603 [81, 82].

- The scale-anchors. These materials are used to perform a two-point data normalisation for the scale. Example materials are SLAP (now replaced by SLAP2) for water and LSVEC (see below) for carbon.

- Secondary reference materials. These materials have been characterised against primary reference materials with their values normalised against the scale-anchors. They have larger uncertainty than the primary reference materials.

- Tertiary level reference materials. While there is no strict formal recognition of tertiary level reference materials there may be a valid case for recognising these in some instances. An example is carbon dioxide gas mixtures prepared and characterised against primary or secondary reference materials (carbonates), such as the JRAS air sets [89]. Other examples include matrix reference materials for $\mathrm{GC}$ combustion applications. In particular, this class of reference material is susceptible to stability issues and there is a need for it to be re-characterised periodically against more stable reference materials. Tertiary level materials have larger uncertainty than secondary reference materials

- Working laboratory standards. These are generally produced for specific laboratory applications and have the largest uncertainty that includes uncertainty from the reference material used to assign values and a component introduced by the two-point data normalisation.

The uncertainty introduced by the two-point data normalisation is intrinsic to all secondary and tertiary reference materials as well as working laboratory standards. Often a pair of reference materials is used for calibration purpose (addressing two-point data normalisation requirement), with a third reference material to be used for quality control.

3.2.2. Developments at the IAEA. Critical uncertainty limits for international reference materials are imposed by $\delta^{13} \mathrm{C}$ observations of atmospheric carbon dioxide. Inter laboratory comparability of such measurements should be within $0.01 \%$ o to allow meaningful comparisons of data [30]. This, as well as the LSVEC-drift found [86, 87] and the strong need for an LSVEC-replacement, supports that IAEA focus on developing new reference materials for $\delta^{13} \mathrm{C}$. Further improvements to the QA/QC, addressing the recently introduced ISO 17034 for reference material producers [90] and comprehensive uncertainty evaluation based on metrological principles have been recommended [15]. Using this new approach, the IAEA-603 preparation [82] included several steps as (i) a batch production of 5000 ampules flushed with argon and sealed off (material has been reserved for production of 4 such batches), (ii) 52 ampoules selected for the homogeneity study; (iii) extensive characterisation study performed at the IAEA. The assigned value $\delta^{13} \mathrm{C}=2.46 \%$ $\pm 0.01 \%$ o $(k=1)$ and $\delta^{18} \mathrm{O}=-2.37 \% \circ \pm 0.04 \%$ o $(k=1)$, for IAEA-603 have a dominating uncertainty component due to homogeneity (type A uncertainty) estimated over 5000 ampoules rather than characterisation measurements against the NBS19 primary reference (type B uncertainty) [82].

Three new carbonate reference materials, under development at the IAEA, have been sealed in glass ampoules in 2018 (around 11000 in total) and material for further batches has been reserved. The development of carbon dioxide gas reference materials is planned to commence in 2019. Both types of reference material will cover a range of $\delta^{13} \mathrm{C}$ and $\delta^{18} \mathrm{O}$ values, have well-characterised uncertainty and be well-preserved to eliminate storage effects. These reference materials will be used for harmonised realisation of the VPDB $\delta^{13} \mathrm{C}$ scale and provide several scale-anchors on the scale. Thus, users will be able to select anchors in the most suitable form (carbonate or carbon dioxide) and with the most appropriate $\delta^{13} \mathrm{C}$ values. In particular, several scale anchors for $\delta^{13} \mathrm{C}$ will help (i) to monitor drifts in $\delta^{13} \mathrm{C}$, if any and (ii) verify exactness of the ${ }^{17} \mathrm{O}$ correction [91] applied in the mass-spectrometry software or in user' calculations. The value and uncertainty assignment for new reference materials shall be based on the traceability to the highest reference materials, careful validation of analytical methods in use and thoughtful assessment of all corrections involved as well as distinguishing type A and type B uncertainty components.

To realise scales independent from the historical artefacts, it is important that the absolute ratios $\left({ }^{13} \mathrm{C} /{ }^{12} \mathrm{C},{ }^{18} \mathrm{O} /{ }^{16} \mathrm{O},{ }^{2} \mathrm{H} /{ }^{1} \mathrm{H}\right.$, ${ }^{15} \mathrm{~N} /{ }^{14} \mathrm{~N}$ ) of the scale-artefacts are determined [15]; current best measurements of the absolute ratios as recommended by IUPAC can be found in Meija et al and references therein [79]. Several attempts to determine the ${ }^{13} \mathrm{C} /{ }^{12} \mathrm{C}$ value of the VPDB scale zero [92-95] have been made, however discrepancies among several ${ }^{13} \mathrm{C} /{ }^{12} \mathrm{C}$ determinations were observed and the absolute ratios are still not known with the uncertainty required for robust scale realisation which, for $\delta^{13} \mathrm{C}$, must be $0.01 \%$ or lower. In addition, with the development of optical spectroscopic methods for stable isotope measurements, it will be necessary to develop reference materials or calibration approaches that allow both mass-spectrometry and optical spectroscopy results to be reported on the same reference scales. The realisation of isotopic scales may not be straight forward for users of optical analysers, i.e. scaling $\delta^{2} \mathrm{H}$ measurements of methane gas to VSMOW (primary reference is water), or $\delta^{13} \mathrm{C}$ measurements of atmospheric carbon dioxide to VPDB (primary reference is carbonate). Therefore, other practical solutions such as optical transfer standards [96] may be considered for the future. For isotopes of atmospheric carbon dioxide, the Jena reference air sets (JRAS), represent standards usable by both optical, and IRMS instruments (see section 3.3). 
Table 4. Delta values of gas reference materials [84, 97-101]. The site preference (SP) is defined as the difference in ${ }^{15} \mathrm{~N}$ substitution between the central $\left(\delta^{15} \mathrm{~N}^{\alpha}\right)$ and terminal $\left(\delta^{15} \mathrm{~N}^{\beta}\right)$ nitrogen position of the nitrous oxide molecule $\left(\mathrm{SP}=\delta^{15} \mathrm{~N}^{\alpha}-\delta^{15} \mathrm{~N}^{\beta}\right)$.

\begin{tabular}{|c|c|c|c|}
\hline $\mathrm{CO}_{2}$ & $\delta^{13} \mathrm{C}_{\mathrm{VPDB}-\mathrm{CO}_{2}}$ & $\delta^{18} \mathrm{O}_{\mathrm{VPDB}-\mathrm{CO}_{2}}$ & Comment \\
\hline NIST RM 8562 & $-3.72 \% \circ \pm 0.035 \% \circ$ & $-18.49 \% \circ \pm 0.22 \% \circ$ & $\mathrm{CO}_{2}$ heavy \\
\hline NIST RM 8563 & $-41.59 \% \circ \pm 0.045 \% \circ$ & $-33.52 \% \circ \pm 0.24 \% \circ$ & $\mathrm{CO}_{2}$ light \\
\hline NIST RM 8564 & $-10.45 \% \circ \pm 0.035 \% \circ$ & $-10.09 \% \circ \pm 0.20 \% \circ$ & $\mathrm{CO}_{2}$ biogenic \\
\hline NARCIS I & $-8.55 \% \circ \pm 0.02 \% \circ$ & $-0.7 \% \circ \pm 0.06 \%$ & \\
\hline NARCIS II & $+1.923 \% \circ \pm 0.003 \% \circ$ & $-2.6 \% \circ \pm 0.06 \%$ & \\
\hline $\mathrm{N}_{2} \mathrm{O}$ & $\delta^{15} \mathrm{~N}_{\mathrm{AIR}-\mathrm{N}_{2}}^{\alpha} / \delta^{15} \mathrm{~N}_{\mathrm{AIR-N} \mathrm{N}_{2}}^{\beta}{ }^{\mathrm{a}}$ & $\delta^{15} \mathrm{~N}_{\text {AIR-N }} / \delta^{18} \mathrm{O}_{\text {VSMOW-SLAP }}{ }^{\mathrm{a}}$ & Comment \\
\hline USGS51 & $+0.48 \% \circ \pm 0.09 \% o /+2.15 \% \circ \pm 0.12 \% \circ$ & $\begin{array}{r}+1.32 \% \circ \pm 0.04 \% \circ \\
+41.23 \% \circ \pm 0.04 \% \circ\end{array}$ & $\mathrm{SP}=-1.67 \%$ \\
\hline USGS52 & $+13.52 \% \circ \pm 0.04 \% o /-12.64 \% \circ \pm 0.05 \% \circ$ & $\begin{aligned}+0.44 \% \circ & \pm 0.02 \% \circ \\
+40.64 \% \circ & \pm 0.03 \% \circ\end{aligned}$ & $\mathrm{SP}=+26.15 \%$ o \\
\hline
\end{tabular}

${ }^{a}$ Delta values are a preliminary assessment provided by Naohiro Yoshida and Sakae Toyoda/Tokyo Institute of Technology. Uncertainties are standard deviations of repeated measurements against the laboratory reference gas and do not include any calibration uncertainties of the laboratory reference gas with respect to AIR-N 2 and VSMOW.

\subsection{Isotopic analyses of atmospheric carbon dioxide, methane and nitrous oxide}

Table 4 presents gas reference materials. A comprehensive list of gas standards for isotope analyses is provided by Brand et al [78].

3.3.1. Carbon dioxide. $\delta^{13} \mathrm{C}$ and $\delta^{18} \mathrm{O}$ isotopic values of atmospheric carbon dioxide are reported on the VPDB and VPDB- $\mathrm{CO}_{2}$ scales respectively. The quantitative conversion of the carbonate to carbon dioxide using the classical method, i.e. the reaction with $100 \%$ phosphoric acid at $25^{\circ} \mathrm{C}$ [102], does not lead to a fractionation of the carbon isotopic signature. However, the oxygen isotopic signature of the carbonate is not preserved as only 2 out of 3 oxygen atoms are transferred to the carbon dioxide molecule with some fractionation involved [100]. This is why $\delta^{18} \mathrm{O}$ values of carbon dioxide gas are reported on the VPDB- $\mathrm{CO}_{2}$ scale, and not on the VPDB scale. Correspondingly, the oxygen isotopic composition of the produced carbon dioxide was found to be dependent on the reaction temperature, the isotopic composition of the acid, its concentration and the water content [103]. Since the results of the phosphoric acid reaction depend on numerous variables, the reaction is one of the limiting factors when considering inter-laboratory comparability of the isotopic composition of carbon dioxide gas. For example, a comparison between three laboratories has shown that carbon dioxide evolved from NBS 19 carbonate varies by no more than $0.003 \%$ in its $\delta^{13} \mathrm{C}_{\mathrm{VPDB}}$ value, but by over $0.1 \%$ in its $\delta^{18} \mathrm{O}_{\mathrm{VPDB}-\mathrm{CO}_{2}}$ value [100]. One way to circumvent this problem is to make standard carbon dioxide gases with certified $\delta^{13} \mathrm{C}_{\mathrm{VPDB}}$ and $\delta^{18} \mathrm{O}_{\mathrm{VPDB}-\mathrm{CO}_{2}}$ values available (NIST RM 8562, NIST RM 8563, NIST RM 8564, NARCIS I, NARCIS II, but table 4 demonstrates that more effort may still be needed).

Since GAW long term data comparability between laboratories requires that the same reference scale realisation be used, the WMO designated the Stable Isotope Lab of the Max Planck Institute for Biogeochemistry (BGC-IsoLab) as CCL for stable isotopic calibrations of measurements on atmospheric carbon dioxide. The BGC-IsoLab developed the JRAS-06 realisation of the VPDB-CO $\mathrm{CO}_{2}$ scale consisting of two carbon dioxide in air mixtures [89, 104]. The carbon dioxide is derived from two carbonates, MAR-J1 $\left(\delta^{13} \mathrm{C}_{\mathrm{VPDB}}:+1.958 \%\right.$ \pm $\left.0.010 \% \circ ; \quad \delta^{18} \mathrm{O}_{\mathrm{VPDB}-\mathrm{CO}_{2}}:-2.578 \% \circ \pm 0.031 \% 0\right)$ and OMC-J1 $\left(\delta^{13} \mathrm{C}_{\mathrm{VPDB}}:-4.373 \% \circ \pm 0.014 \%\right.$; $\delta^{18} \mathrm{O}_{\mathrm{VPDB}-\mathrm{CO}_{2}}:-8.928 \%$ \pm $0.025 \%$ ) [104]. The BGC-IsoLab has developed an automated carbon dioxide preparation system, ARAMIS (acid reaction and mixing system) that is used for the phosphoric acid reaction $[89,103]$ and routinely produces carbon dioxide gas from carbonates, including primary international reference materials, with a precision of $0.01 \%$ and $0.03 \%$ ofor $\delta^{13} \mathrm{C}_{\mathrm{VPDB}}$ and $\delta^{18} \mathrm{O}_{\mathrm{VPDB}-\mathrm{CO}_{2}}$, respectively. The produced carbon dioxide is mixed into carbon dioxide free air achieving an amount fraction close to ambient, and these mixtures are then analysed by cryogenically extracting the carbon dioxide [89] in order to assign $\delta^{13} \mathrm{C}_{\mathrm{VPDB}}$ and $\delta^{18} \mathrm{O}_{\mathrm{VPDB}-\mathrm{CO}_{2}}$ values. Since the mixing procedure and subsequent analyses introduces only small isotopic offsets between the pure carbon dioxide, and that mixed into carbon dioxide free air [100], isotopes of carbon dioxide in air are reported on the JRAS-06 scale realisation of the VPDB- $\mathrm{CO}_{2}$ scale.

3.3.2. Methane. The ${ }^{13} \mathrm{C} /{ }^{12} \mathrm{C}$ and ${ }^{2} \mathrm{H} /{ }^{1} \mathrm{H}$ isotope ratios of methane are reported on the VPDB and the VSMOW scale, respectively. The first $\delta^{13} \mathrm{C}$ measurements on atmospheric methane were made at the National Institute for Water and Atmosphere Research (NIWA, NZ) [105]. A barium carbonate standard (NZCH, later distributed as IAEA-CO-9) and a carbon dioxide standard gas (NBS-16) were used to standardise measurement results. These reference materials, recharacterised against LSVEC in 2006 [85], offered by NIST and IAEA in the past, are now exhausted.

Most laboratories have developed their own lab-standards and associated protocols to link $\delta^{13} \mathrm{C}$ and $\delta^{2} \mathrm{H}$ methane isotope data to the VPDB-, and VSMOW-scales, respectively [106]. The use of different calibration approaches in laboratories, different laboratory standards, inconsistent use of the 
${ }^{17} \mathrm{O}$ correction and not correcting for instrumental memory and cross-contamination have contributed to inter-laboratory measurement offset of up to $0.5 \%$ for $\delta^{13} \mathrm{C}$, and up to $13 \%$ o for $\delta^{2} \mathrm{H}$ measurements of atmospheric methane isotopes [106]. These inter-laboratory offsets clearly indicate that a unified effort needs to be undertaken to improve calibrations [106].

The most recent work linking isotopes of methane to primary reference materials was undertaken by Sperlich et al [107]. They selected a suite of pure methane gases that are directly characterised in the $\delta^{13} \mathrm{C}_{\mathrm{VPDB}}$ and $\delta^{2} \mathrm{H}_{\mathrm{VSMOW}-\mathrm{SLAP}}$ values via elemental analyses (EA) and high temperature conversion (HTC) IRMS techniques, respectively. Significantly, the $\delta^{13} \mathrm{C}$ values of the methane gases were calibrated using LSVEC as a scale anchor, which means that these values may need to be revised once an LSVEC replacement is available. To address commutability requirements and have reference materials as close in composition as possible to samples, calibrated methane gas was mixed into methane free air, and these mixtures used to calibrate the working standard for methane in air measurements at the BGC-IsoLab [108]. $\delta^{2} \mathrm{H}-\mathrm{CH}_{4}$ scales linked to the $\delta^{2} \mathrm{H}_{\text {VSMOW-SLAP }}$ scale and based on synthetic mixtures of pure isotopologues [109] are in use at the Max-PlanckInstitute for Chemistry in Mainz, Germany, and the Institute for Marine and Atmospheric research in Utrecht, Netherlands [106]. However, we note that the work by Sperlich et al [107] is the first attempt to generate a $\delta^{2} \mathrm{H}-\mathrm{CH}_{4}$ methane in air mixture that is directly traceable to primary reference materials.

3.3.3. Nitrous oxide. ${ }^{15} \mathrm{~N} /{ }^{14} \mathrm{~N}$ and ${ }^{18} \mathrm{O} /{ }^{16} \mathrm{O}$ isotope ratios of nitrous oxide are reported on the AIR- $\mathrm{N}_{2}$ and the VSMOW scale, respectively. Being an asymmetric linear molecule the central $(\alpha)$ and terminal $(\beta)$ nitrogen atoms of nitrous oxide provide position-specific $\delta^{15} \mathrm{~N}_{\text {AIR-N }}$ isotopic information [110]. The difference between $\delta^{15} \mathrm{~N}_{\text {AIR-N }}$ values of the central $\left(\delta^{15} \mathrm{~N}^{\alpha}\right)$ and terminal $\left(\delta^{15} \mathrm{~N}^{\beta}\right)$ nitrogen position of the nitrous oxide molecule is called site preference and defined as $\mathrm{SP}=\delta^{15} \mathrm{~N}^{\alpha}-\delta^{15} \mathrm{~N}^{\beta}$, while the average $\delta^{15} \mathrm{~N}_{\text {AIR- } \mathrm{N}_{2}}=\left(\delta^{15} \mathrm{~N}^{\alpha}+\delta^{15} \mathrm{~N}^{\beta}\right) / 2$. The synthesis of nitrous oxide by the thermal decomposition of isotopically characterised ammonium nitrate has been suggested as an approach to link the position-dependent nitrogen isotopic composition of nitrous oxide to AIR- $\mathrm{N}_{2}$ [110]. During decomposition, the nitrogen atom of the $\mathrm{NO}_{3}^{-}$ion is converted into the central nitrogen position of $\mathrm{N}_{2} \mathrm{O}$, while the end nitrogen comes from the $\mathrm{NH}_{4}^{+}$ion. However, the accuracy of this approach for the calibration of $\delta^{15} \mathrm{~N}^{\alpha}$ and $\delta^{15} \mathrm{~N}^{\beta}$ was found to be limited by nonquantitative ammonium nitrate decomposition in combination with substantially different isotope enrichment factors for the conversion of the $\mathrm{NO}_{3}^{-}$or $\mathrm{NH}_{4}^{+}$nitrogen atom into the $\alpha$ or $\beta$ position of the nitrous oxide molecule [111]. The yield of the ammonium nitrate decomposition reaction to nitrous oxide was found to be dependent on reaction conditions, e.g. temperature, which impedes the implementation of this technique in many laboratories [112]. Consequently, the compatibility between eleven IRMS and laser spectroscopy laboratories was found to be limited to approximately $6 \%$ o for the nitrous oxide site preference [113]. In order to overcome such experimental artefacts when comparing data between laboratories, two new nitrous oxide reference gases, USGS51 and USGS52 have been produced [98] and are available (table 4). The delta values provided for USGS51 and USGS52 are based on a preliminary assessment by Naohiro Yoshida and Sakae Toyoda/Tokyo Institute of Technology without uncertainty estimates and offer only a small range of $\delta^{15} \mathrm{~N}$ and $\delta^{18} \mathrm{O}$ values $(<1 \%$ ) , they are not suitable for a two-point calibration. Therefore, novel nitrous oxide reference materials are being developed within the European Metrology Programme for Innovation and Research (EMPIR) 16ENV06 project 'Metrology for Stable Isotope Reference Standards (SIRS)' [114]. Reference materials will be available as pure gas, to be used directly for traditional mass-spectrometry and/or for mixture preparation by users and as nitrous oxide diluted in whole air for laser spectroscopic measurement techniques.

\section{Advances in measurement techniques}

Prior to the development of modern commercial spectroscopic analysers, atmospheric carbon dioxide, methane, and nitrous oxide were most frequently measured using gas chromatography where packed columns containing Porapak Q or Hayesep Q are used to separate these components from other air components. Detection is accomplished using a flame ionization detector (FID) (for methane and carbon dioxide after conversion to methane on a nickel catalyst in the presence of hydrogen) or an electron capture detector (ECD) (for nitrous oxide) [115-118]. The linear response of an FID makes the GC method an attractive technique for quasi-continuous sampling. Repeatability standard deviations of approximately $0.1 \mu \mathrm{mol} \mathrm{mol}{ }^{-1}$ and $1 \mathrm{nmol} \mathrm{mol}{ }^{-1}$ can be achieved for carbon dioxide and methane, respectively [115]. For nitrous oxide, a repeatability standard deviation of $0.1 \mathrm{nmol} \mathrm{mol}^{-1}$ is possible using GC-ECD, but this is difficult to achieve (0.2-0.3 nmol mol $\mathrm{m}^{-1}$ is more typical) and the response is typically non-linear requiring careful attention to calibration strategy $[115,119]$. Detection of nitrous oxide by ECD is indirect (i.e. there is no net electron capture). It requires a dopant gas, such as methane, oxygen, or carbon dioxide, to facilitate electron capture [120]. Thus, nitrous oxide analysis by GC-ECD is typically carried out using 5\% argon in methane (P-5), or carbon dioxide doped nitrogen [57] as a carrier gas. High-precision work using GC methods requires high-quality carrier gases, particularly with respect to nitrous oxide.

For carbon dioxide, NDIR methods were more common than GC methods and are still used. An advantage of the NDIR method is that the analysers are relatively inexpensive and robust. However, their response tends to be non-linear, and frequent (sub-daily) calibration over a range of amount fractions is typically required. Repeatabilities of a few $\mathrm{nmol} \mathrm{mol}^{-1}$ can be achieved with care $[72,116,121]$. It is also important to consider matrix effects, including those related to carbon dioxide in air versus carbon dioxide in nitrogen [122, 123], and those related to the relative abundances of stable isotopes of carbon dioxide between samples and standards [47]. Analyser response to the minor isotopologues of carbon dioxide, such as ${ }^{16} \mathrm{O}^{13} \mathrm{C}^{16} \mathrm{O}$, can vary among analysers, even 
from the same manufacturer [124]. This can lead to small, and difficult to quantify, calibration offsets when samples and reference standards differ in the carbon dioxide isotopic composition. Tohjima et al [124] compared ambient air samples $\left(\delta^{13} \mathrm{C}_{\mathrm{VPDB}} \approx-8 \%\right.$ ) to isotopically light references $\left(\delta^{13} \mathrm{C}_{\mathrm{VPDB}} \approx-32 \%\right)$, and found offsets that ranged from -0.04 to $-0.08 \mu \mathrm{mol} \mathrm{mol}{ }^{-1}$ among different NDIR instruments.

\subsection{Isotope ratio mass spectrometry}

The basic measurement principle for high precision analyses of light (carbon, nitrogen, oxygen and hydrogen) stable isotopes was introduced by Nier in 1947 [125]. There are now numerous publications and text books with detailed histories and explanations on the measurement principles and applications of IRMS [126-128]. IRMS instruments measure gases introduced into a 'Nier-Type' ion source and ionised by a tightly collimated stream of electrons [129]. The resultant ions leaving the ion source are accelerated into the magnetic analyser, where the ions are separated based on their mass to charge ratio. The discrete ion beams at integral masses are simultaneously detected with a number of Faraday cups that measure the number of ions arriving in the form of an induced electrical current [130]. The typical sensitivity of a modern IRMS, defined as the number of molecules needed to detect an ion, is between 1000-2000 molecules, depending on the component gas and instrumental parameters.

Modern IRMS systems may be operated in dual-inlet- or continuous flow-mode. Dual-inlet measurements are achieved using a system of gas filled fixed and/or variable volumes that are connected via a changeover valve to the ion source that allows direct comparative measurements of two gases [131]. This system enables high-precision measurements for carbon isotopes of carbon dioxide of $0.01 \%$ or better [132]. Continuous flow mode allows the IRMS to be coupled to numerous preparative analytical systems, such as elemental analysers [133, 134], or high temperature coupled to gas chromatograph separation columns $[135,136]$. These systems enable the on-line analysis of different sample types by combustion, although at lower precision than dual inlet mode. The produced gas is introduced into the IRMS in a carrier gas stream (usually helium). The advent of this technique has made IRMS technique useful to a wide range of analytical fields including, but not limited to geochemistry and food authentication [137, 138].

The interest in clumped isotope analysis [139] has necessitated the development of higher resolution IRMS systems. Separating isotopologues with more than one rare isotope and isotopologues that have the same cardinal mass (e.g. ${ }^{12} \mathrm{C}^{18} \mathrm{O}^{16} \mathrm{O}$ and ${ }^{13} \mathrm{C}^{17} \mathrm{O}{ }^{16} \mathrm{O}$ ) requires very high mass resolution and ultra-clean baselines. Double focusing mass analysers reduce the energy dispersion of the ions, allowing the sector field to produce more focused ion beams which increases mass resolution [140, 141]. Interference from the high and low energy tails of adjacent masses is also suppressed.

\subsection{Cavity ring-down spectroscopy and off axis} integrated-cavity-output spectroscopy

CRDS was introduced by O'Keefe and Deacon three decades ago as an ultrasensitive laboratory technique for measuring gas-phase absorption spectra [142]. Since its inception, more than 4000 CRDS-based research articles have appeared in the peer-reviewed scientific literature testifying to the impact of the method. Although most CRDS applications involve gas samples, the technique also can be used to measure aerosols $[143,144]$ and liquids [145]. Useful reviews of CRDS and its applications can be found in [146-148] and references therein.

In CRDS, a laser beam enters an optical resonator comprising at least two high-reflectivity mirrors and containing the sample. Turning off the laser light leads to an exponential decrease of the light intensity exiting the resonator with a decay rate depending on the mirror losses and sample absorbance. Unlike transmission-based techniques, this measurement is immune to intensity fluctuations in the light source as it is the decay (ring down) that is measured. Moreover, exceptionally long effective pathlengths (on the order of tens of $\mathrm{km}$ ) in a compact mode volume (mm-scale diameter) and highspectral resolution (sub MHz-level) can be realised. Early demonstrations of CRDS used pulsed lasers [149-151], and by the early 2000s these sources were largely supplanted by tunable single-frequency continuous-wave diode lasers (CWDLs) available throughout the visible, near-infrared and midinfrared spectral regions [152-155].

For an isolated absorption transition, the peak area equals the product of absorber number density and line intensity, independently of pressure-broadening mechanisms affecting the line shape. With single-frequency cavity excitation, spectral line shapes and peak areas can be accurately determined from observed decay times and optical frequency shifts [156, 157]. In this case, CRDS (similar to TDLAS in section 4.3) is an SI-traceable measurement of amount provided that the line intensity is known and the pressure-broadening mechanism is well understood. Ideally the line intensity constitutes an intrinsic standard, eliminating the need for calibration. In most applications, however, SI-traceability of CRDS spectra is achieved by calibration against gas standards, which are valid only for a particular set of conditions (e.g. spectrometer configuration, pressure, temperature and matrix gas composition) [158].

There are several methods for determining the line intensity. Data are usually analysed by fitting the peak area of a normalised line profile to the measured spectrum $[159,160]$. Line intensity determinations from multiple spectroscopic observations can also be analysed and combined by global fits of semi-classical, effective dipole moment surfaces (DMSs) [161]. A third approach for determining line intensities is based on $a b$ initio calculations of the DMS and measured potential energy surfaces (PESs) [162, 163] of the active components. These calculations compare favourably with measurements, with agreement at the $0.5 \%$ level for many examples [164-166]. For all cases, the temperature dependence of the line intensity can be calculated based on the lower state energy, transition frequency and partition function [163]. 
When intensities are known a priori without reference to previous absorption measurements, high spectral resolution optical techniques like CRDS or TDLAS can be treated as a potential primary measurement for amount.

Spectra fitted using the Voigt profile (a probability distribution given by a convolution of a Cauchy-Lorentz distribution and a Gaussian distribution) yields relatively large systematic $W$-shaped fit residuals, resulting in fitted areas that usually underestimate the actual peak area [167]. Therefore, more advanced line profiles are required to minimise peak-area bias. Profile-dependent deviations in peak area ranging from $0.2 \%$ to $2 \%$ have been reported for CRDS measurements of carbon monoxide and water [164, 168]. However, when using line profiles with at least one more degree of freedom than the Voigt, relative differences between fitted areas are nominally $0.05 \%$ and difficult to distinguish. In the last decade line intensity measurements with relative uncertainties typically near $1 \%$ and approaching $0.1 \%$ have been reported [160, 165, 169, 170]. Accurate measurements have also been reported using other techniques including traditional FTIR (see section 4.4), and direct TDLAS (see section 4.3) and cavity-enhanced laser spectroscopy methods. Importantly, these measurements now provide the most stringent tests of $a b$ initio calculations which are contributing to spectroscopic line lists [159, 165, 171].

High sensitivity transmission measurements can also be achieved using the OA-ICOS technique [172-174]. OA-ICOS also uses high-reflectivity mirrors to produce an optical resonator with an effective pathlength much longer than the cell length, with reported pathlengths up to $27.5 \mathrm{~km}$ [175]. The offaxis cavity excitation results in a near-continuum of transverse spatial modes in the cavity; nearly eliminating the frequency selectivity of the optical cavity and making the spectrometer insensitive to cavity alignment. However, because it is difficult to model the spectrally resolved instrument function, converting measured transmitted spectra to amount requires instrument-specific calibration against reference gas mixtures and for equivalent matrix gases. Nevertheless, amount fraction detection limits of $\sim 10^{-10} \mathrm{~mol} \mathrm{~mol}^{-1}$ or below are achievable for infrared transitions of small molecules including carbon monoxide, carbon dioxide and water. OA-ICOS analysers have been used to measure amount and isotopologue ratios of carbon dioxide and methane [176], oxygen [177] and water [178]. Other applications include rapid measurements of gas flux and eddy covariance [179] as well as real-time chemical process measurements [180] and open-path emissions monitoring [181].

\subsection{Tunable diode laser absorption spectroscopy}

Laser absorption spectroscopy (LAS) [182] is a powerful tool for gas analysis and nearly as old as the laser itself. LAS converts the laser's extreme spectral resolution and power density into high chemical selectivity and sensitivity. Tunable diode laser (TDL) based LAS (i.e. TDLAS) strongly spurred industrial [183] and environmental [184] diagnostics. Continuous technical TDL advantages in the meantime allow compact, portable, field-deployable TDLAS instruments, which

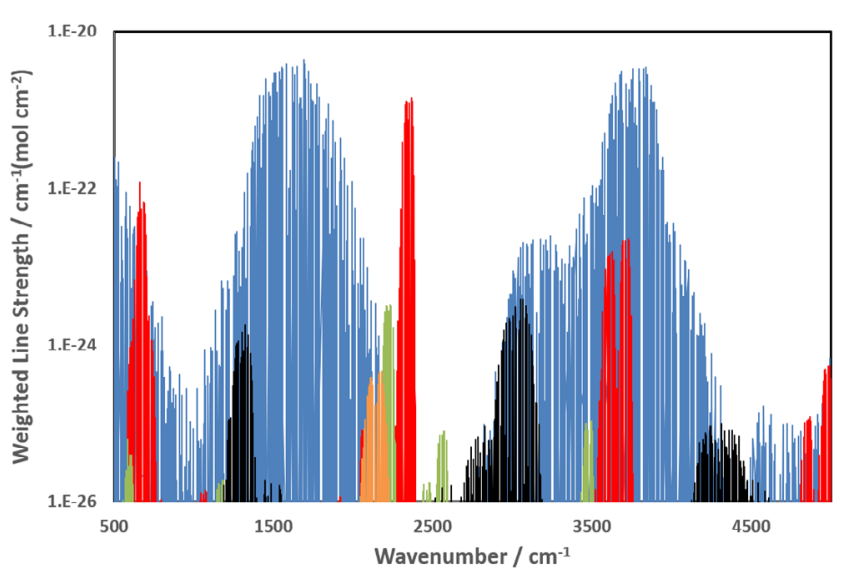

Figure 6. Ro-vibrational transitions of greenhouse gases in the MIR spectral range $\left(500-5000 \mathrm{~cm}^{-1}\right)$, retrieved from the HITRAN database for water (blue), carbon monoxide (orange), methane (black), carbon dioxide (red) and nitrous oxide (green). The line strength of each component is weighted by its abundance in the atmosphere.

routinely realise near real-time gas analysis with up to pmol $\mathrm{mol}^{-1}$ precision $[185,186]$. This made TDLAS a complementary technique for quantification of greenhouse gases and because of their highly characteristic rotational-vibrational transitions, the respective singly and doubly substituted isotopic components (figure 6) [187]. Several examples include the analysis of ${ }^{12} \mathrm{C}^{16} \mathrm{O},{ }^{12} \mathrm{C}^{17} \mathrm{O},{ }^{12} \mathrm{C}^{18} \mathrm{O}[188],{ }^{13} \mathrm{CO}_{2},{ }^{12} \mathrm{CO}_{2}$ [189], $\mathrm{N}_{2}{ }^{16} \mathrm{O}, \mathrm{N}_{2}{ }^{18} \mathrm{O}$ [190] and ${ }^{12} \mathrm{CH}_{4},{ }^{13} \mathrm{CH}_{4},{ }^{12} \mathrm{CH}_{3} \mathrm{D}$ [109]. Recently $\mathrm{H}_{2}{ }^{16} \mathrm{O}, \mathrm{H}_{2}{ }^{18} \mathrm{O}$ has been analysed even inside ice clouds by TDLAS employing NIR DFB lasers [191, 192]. Quantum Cascade Laser (QCL) based isotope ratio measurements were demonstrated for carbon dioxide $\left(\delta^{13} \mathrm{C}, \delta^{18} \mathrm{O}\right)[193$, 194], $\mathrm{N}_{2} \mathrm{O}\left(\delta^{15} \mathrm{~N}^{\alpha}, \delta^{15} \mathrm{~N}^{\beta}, \delta^{18} \mathrm{O}\right)[195,196]$ methane $\left(\delta^{13} \mathrm{C}, \delta \mathrm{D}\right)$ [197] and most recently for the analysis of the doubly substituted so called 'clumped' carbon dioxide, nitrous oxide $\left(\delta^{15} \mathrm{~N}^{14} \mathrm{~N}^{18} \mathrm{O}, \delta^{14} \mathrm{~N}^{15} \mathrm{~N}^{18} \mathrm{O}, \delta^{15} \mathrm{~N}^{15} \mathrm{~N}^{16} \mathrm{O}\right)$ [198] and methane $\left(\delta^{13} \mathrm{CH}_{3} \mathrm{D}\right)$ [199]. High precision analysis for isotopic components with very low abundance at ambient amount fractions is currently realised via a combination of laser spectroscopy with pre-concentration $[197,200]$.

The success of gas analytical TDLAS is driven by persistent improvements in wavelength coverage and commercialisation of novel laser architectures like QCL [201, 202], or inter-sub-band cascade lasers (ICLs) [203-205]. TDLAS in general covers isolated absorption features by laser-current induced wavelength tuning, while laser embedded distributed feedback (DFB) structures ensure monochromatic emission [206]. Scanning frequencies beyond $10 \mathrm{kHz}$ allow measurement times below $100 \mu \mathrm{s}$, particular interesting e.g. for trace gas flux sensors using eddy correlation techniques [207-209] or even high-speed engine analysers $[210,211]$. The 'extractive' TDLAS configuration uses absorption cells at stable pressure, temperature, path length and matrix gas composition. A photodetector captures wavelength dependent light losses described by the Beer-Lambert Law [212] and relates to path-averaged absorber number densities hence component amount fraction [213, 214]. 
A TDLAS instrument is usually built and optimised for 1-2 molecular or isotopic species per laser. However, various multiplexing techniques [215] working in the time-, wavelength- or modulation-frequency-domain enable multi-species instruments combining four and more lasers [216, 217]. Development of integrated dual-wavelength lasers [218, 219], electrically tunable QCL devices or laser arrays will allow developing spectrometers capable of measuring up to 10 components.

TDLAS variants such as direct absorption (dTDLAS) [220], wavelength modulation (WMS) [184, 221, 222] or integrative spectroscopy [223], balance electronic or spectroscopic complexity against noise suppression enabling $10^{-3}$ to $10^{-6}$ fractional absorptions, ultimately approaching shot noise [224]. Rapid electronic modulation multiplexing allowed development of hybrid versions which directly combine WMS and dTDLAS [225].

In general, TDLAS-sensitivity scales linearly with path length $L$, line strength $S$, and gas pressure $p$ (for $p<$ few 10 mbar) and with the square root of measurement time $t^{1 / 2}$ or electronic bandwidth $(1 / \mathrm{BW})^{1 / 2}$ if white noise-limited. Numerous optical multi-pass concepts are used to improve sensitivity, e.g. from White [226], or Herriott and Schulte [227], or improved versions with better volume to path ratio [228], lower weight [229], or size [230], for airborne applications or with special beam geometry [231, 232] e.g. for drones.

In common 'calibrated TDLAS' the system response (sensitivity, accuracy, linearity, stability) is characterised via comparison with a set of known gas mixtures, which entirely ensures traceability. TDLAS of isotopic species does not require corrections for mass interferants, e.g. ${ }^{17} \mathrm{O}$ and $\mathrm{N}_{2} \mathrm{O}$ for $\delta^{13} \mathrm{C}-\mathrm{CO}_{2}$ analysis, like IRMS, but spectral interferences from other atmospheric components may occur and have to be tested and corrected. In addition, the gas matrix of calibration and sample gas have to be closely matched and therefore WMO-GAW recommends the use of 'air standards' for calibration and drift-correction of optical instruments. Static carbon dioxide and nitrous oxide isotopic reference materials in whole air and at ambient amount fractions will be developed within the European metrology project SIRS [114]. In summary, TDLAS can achieve similar precision levels to state-of-the-art IRMS for many components with the advantage of high selectivity and real-time data availability.

The most attractive feature of direct TDLAS (dTDLAS) is its first principles potential [233, 234], i.e. employs a full absorption model to yield absolute species concentrations without instrument calibration, and hence acts as optical gas standard, OGS,--similar to the ozone SRP [235]. Such TDLAS-OGS require absolute values of all input parameters (e.g. $p, T, L$ ), accurate frequency linearization, dynamic laser tuning [169], line shape models [167, 236] and all relevant spectral parameters (e.g. line strength, collisional broadening parameters etc). Accurate $(<1 \%)$, metrologically defined spectral data [237], have been measured recently for ammonia [238], water [214, 239], hydrogen chloride [240, 241], nitrous oxide [242, 243], carbon dioxide [244], and carbon monoxide [245], but are frequently a leading source of uncertainty in TDLAS OGS-realisation. Furthermore, in dTDLAS, high path length cells require accurate length determination [246], while short cells, ask for careful suppression of parasitic absorption contributions [247].

'Calibration-free' TDLAS measurements are very frequently 'claimed', but rarely metrologically scrutinised. Few TDLAS-OGS are solidly validated using primary reference gases, e.g. for carbon dioxide [248] or carbon monoxide in biogas [249]. One of them could be shown to fulfil WMO requirements in the OGS-mode, which should be interesting for very remote field applications. The most mature TDLASOGS-realisations are the two laser-hygrometers, SEALDH [233] and HAI [250], which were successfully validated in $[251,252]$ side by side comparisons with primary metrological humidity generators, but were also successfully used in numerous harsh airborne field-applications [253, 254]. For example SEALDH-II is a fully validated transfer standard which offers an extraordinary relative temperature stability of the humidity signal of $0.026 \% \mathrm{~K}^{-1}$, and an optimum precision of $56 \mathrm{nmol} \mathrm{mol}^{-1}\left(0.125 \mu \mathrm{mol} \mathrm{mol}{ }^{-1} \mathrm{~m}^{-1} \mathrm{~Hz}^{-1 / 2}\right)$. A relative stability of $0.5 \%$ (close to the primary water standard) was demonstrated [255] under metrological conditions. SEALDH-II nevertheless fits in a 4HU 19" rack and only needs a power supply. This successful primary TDLAS-OGS validation [256] and extended field application nicely demonstrates that TDLAS offers great opportunities to generalise the realisation of primary OGS to a broad range of molecules.

\subsection{Fourier transform infra-red spectroscopy}

FTIR [257, 258] is a well-established analytical technique that offers an approach to trace gas analysis complementary to that offered by laser-based methods (sections 4.2 and 4.3). FTIR is a broadband technique covering a wide spectral range using a thermal light source. Analysis of the broadband FTIR spectrum allows the retrieval of concentrations of several trace gases simultaneously from a measured spectrum. An FTIR spectrometer typically consists of a broadband source (globar in the mid infrared (MIR) or halogen lamp in the near infrared (NIR)), an interferometer, sample cell (usually multi-pass for enhanced absorption) and IR detector. The instrument records an interferogram which is Fourier transformed into an infrared spectrum. A transmittance or absorbance spectrum is constructed by dividing the sample spectrum by a pre-measured spectrum of the empty sample cell. For quantitative analysis the spectrum is typically analysed over a broad spectral range encompassing many thousands of (overlapping) spectral lines in contrast to laser techniques which exploit the high resolution of the laser at low sample pressure to analyse single rotational-vibrational lines of molecular species in the spectrum. FTIR and laser techniques achieve comparable precisionsthe high brightness of the laser source over a single rovibrational line on the one hand is balanced by the broad spectral range and analysis of many thousands of lines that allow the simultaneous quantification of component and impurities on the other.

Peak height or area-based quantitative analysis of single absorption lines is not appropriate to the lower spectral resolution of FTIR compared to laser spectroscopy due to 
spectral line overlapping at the lower spectral resolution and in samples that may be at atmospheric pressure. Quantitative spectrum analysis typically uses either chemometric techniques or non-linear least squares fitting over whole or partial spectral bands to retrieve trace gas amounts from spectra. In chemometric techniques such as classic least squares (CLS) $[259,260]$ or partial least squares (PLS) [259, 261], the best fit to a measured absorbance spectrum is constructed as a linear combination of pure single component spectra, or factors derived from a principal components analysis. Chemometric techniques are based on the Beer-Lambert Law and its implied linearity between absorbance and concentration, which breaks down at low resolution and introduces non-linearity into the calibration. In non-linear least squares analysis [258, 262] a transmittance spectrum is calculated from absorption line parameters (the forward model) and the parameters of the model, including the trace gas amounts, are iteratively adjusted to achieve best fit to the measured spectrum (the inverse model).

FTIR analysis has been used in many applications of industrial and pollution monitoring, but here we restrict the history to measurements of atmospheric greenhouse gases focused on high accuracy and traceability to SI standards. Esler et al $[263,264]$ provided the first such measurements using a commercial FTIR spectrometer, $9.6 \mathrm{~m}$ White cell and liquid nitrogen cooled MCT detector to measure carbon dioxide, methane, nitrous oxide, carbon monoxide and $\delta^{13} \mathrm{C}$-in- $\mathrm{CO}_{2}$ simultaneously in air samples. The spectra were analysed by CLS using synthetic reference single component spectra calculated at the temperature and pressure of the measurement $[259,265]$. This FTIR system was developed further to improve accuracy and precision using least squares spectrum analysis, and ease of use in the field, and is described in detail by Griffith et al [262].

In parallel to this development, Mohn et al [261, 266] used a laboratory FTIR spectrometer and White cell combined with PLS chemometric analysis focussed on $\delta^{13} \mathrm{C}$-in- $\mathrm{CO}_{2}$ measurements in field applications, but also including measurements of methane, nitrous oxide and carbon monoxide.

At the BIPM, Flores, Viallon and co-workers assessed FTIR in metrological trace gas applications and applied this technique to underpin international comparisons among NMIs [20, 267-271]. At the BIPM a laboratory FTIR system has been refined for $\delta^{13} \mathrm{C}$ measurements in carbon dioxide with a formal assessment of errors [49]. This work demonstrated a new approach to isotopic measurements described below in which a range of $\delta^{13} \mathrm{C}$ in standard gases is not required-the calibration is based on isotopologues rather than isotope ratios and it is sufficient that the calibration standards cover only the range of isotopologue concentrations or amount fractions.

In principle, the quantitative analysis methods described above can be traceable to the SI. Quantitative reference library spectra or line parameter databases should be traceable, i.e. calibrated and with an uncertainty estimation, but this is rarely the case. Work at Physikalisch-Technische Bundesanstalt (PTB) intends to address these deficits by establishing a European spectroscopy infrastructure to produce traceable measurements of spectral line data under well controlled conditions at a central spectroscopic facility (EUMETRISPEC) [272]. The limitation in estimating uncertainty of FTIR measurements comes from the forward model used to calculate spectra: both the true spectral and instrument line-shapes are not accurately known, and the forward model is an approximation of the true molecular and instrument line-shape functions. Approaches other than the analytical uncertainty estimation must be employed, such as the sensitivity study developed by Flores et al [273] for determining the uncertainty of laboratory-based measurements of nitrogen dioxide and nitric acid amount fractions. This method may be useful when no reference gas standard is available, but the uncertainties are close to $5 \%$ to $10 \%$. To reach lower uncertainties, as with the laser-based techniques, FTIR measurements of air must be calibrated against reference standard gases and the normal approach is calibration against reference gases traceable to primary SI quantities through NMIs and/or the WMO-GAW calibration laboratories.

Spectroscopic analysers are inherently isotopologue specific in their response because molecular rotation-vibration spectra depend on the masses of the constituent atoms. The output of an optical analyser thus depends on the isotopic composition of the measurand. In practice, optical spectroscopic analysers can be used for explicit measurements of isotopic fractionation and as a proxy for total trace gas amounts. In the former case the individual isotopologues are measured as independent components and there is no inherent ambiguity. In the latter case a total trace gas amount measured by the optical analyser based on a specific isotopologue can only be accurately calibrated if isotopic composition is not significantly different between the sample and the reference standard. Differences in isotopic composition may in some cases lead to significant errors in deriving total trace gas amounts from an optical measurement. Recent works have quantified this potential for error and provided the strict calculations required to calculate trace total amounts from isotopologue measurements. The potential errors should be assessed when using any optical spectroscopic technique [52, 274, 275].

\section{Conclusions and outlook}

The developments in reference materials and measurement techniques for underpinning atmospheric amount fraction measurements of three key greenhouse gases (carbon dioxide, methane and nitrous oxide) as well as isotopic composition for source apportionment have been reviewed. Substantial progress has been made in recent years, particularly within the CCQM-GAWG and WMO-GAW towards providing a measurement infrastructure to underpin accurate and reliable measurements. However there remains an urgent requirement for further developments. Future work is focussed on the next generation of greenhouse gas reference materials, which will be value assigned for amount fraction and isotope ratio and matrix matched to atmospheric compositions, providing instrument manufacturers and atmospheric scientists with the standards required to monitor amount fractions and isotope ratios accurately in real time. There is also a significant focus towards a more robust metrology infrastructure for isotope 
ratio underpinned by new reference materials and advances in instrumentation.

\section{Acknowledgments}

This work was funded, in part, by the United Kingdom National Measurement System. Christoph Zellweger acknowledges funding from the World Calibration Centre WCC-Empa which is supported by MeteoSwiss and Empa.

\section{ORCID iDs}

Paul J Brewer (10 https://orcid.org/0000-0002-7446-417X Sangil Lee (1) https://orcid.org/0000-0001-7912-2841 Joële Viallon (1) https://orcid.org/0000-0001-8934-9484 Takuya Shimosaka (i) https://orcid.org/0000-0002-1727-285X Sergey Assonov (1) https://orcid.org/0000-0001-9096-4150 Colin Allison (1) https://orcid.org/0000-0002-7796-6917 Adriaan M H van der Veen (1) https://orcid.org/0000-00029648-5123

Joachim Mohn (1) https://orcid.org/0000-0002-9799-1001

Heiko Moossen (D) https://orcid.org/0000-0003-4768-2603

Volker Ebert (10 https://orcid.org/0000-0002-1394-3097

David Griffith (1) https://orcid.org/0000-0002-7986-1924

\section{References}

[1] Kyoto Protocol 2018 United Nations framework convention on climate change (www.unfccc.int. (Accessed: December 2018))

[2] www.cop21paris.org/about/cop21/ (Accessed: December 2018)

[3] www.ipcc.ch/sr15/ (Accessed: December 2018)

[4] https://library.wmo.int/doc_num.php?explnum_id=4022 (Accessed: December 2018)

[5] Keeling R F, Piper S C and Heimann M 1996 Global and hemispheric $\mathrm{CO}_{2}$ sinks deduced from changes in atmospheric $\mathrm{O}_{2}$ concentration Nature 381 218-21

[6] Conway T J, Tans P P, Waterman L S, Thoning K W, Kitzis D R, Masarie K A and Zhang N 1994 Evidence for interannual variability of the carbon cycle from the National Oceanic and atmospheric administration/climate monitoring and diagnostics laboratory global air sampling network J. Geophys. Res. 99 22831-55

[7] NOAA/ESRL/GMD Website (www.esrl.noaa.gov/gmd/ccgg/ trends/global.html (accessed: October 2018))

[8] Rhoderick G C, Kitzis D R, Kelley M E, Miller W R, Hall B D, Dlugokencky E J, Tans P P, Possolo A and Carney J 2016 Development of a Northern continental air standard reference material Anal. Chem. 88 3376-85

[9] Pachauri R K and Reisinger A (eds) 2007 Fourth Assessment Report of the Intergovernmental Panel on Climate Change (Geneva: IPCC), ch 2

[10] library.wmo.int/doc_num.php?explnum_id=5455 (Accessed: December 2018)

[11] www.wmo.int/pages/prog/arep/gaw/gaw_home_en.html (Accessed: December 2018)

[12] www.bipm.org/utils/en/pdf/CCQM-strategy-document.pdf (Accessed: December 2018)

[13] International equivalence of measurements: the CIPM MRA (www.bipm.org/en/cipm-mra/ (Accessed: December 2018))

[14] Climate Change 2007 The physical Science Basis, contribution of working group I to the fourth assessment report of the intergovernmental panel on climate change
[15] Assonov S 2018 Summary and recommendations from the International Atomic Energy Agency Technical Meeting on the Development of Stable Isotope Reference Products (21-25 November 2016) Rapid Commun. Mass Spectrom. 32 827-30

[16] CCQM Working Group on Gas Analysis (CCQM-GAWG) (www.bipm.org/en/committees/cc/wg/gawg.html (Accessed: December 2018))

[17] Brown R J C, Brewer P J, Harris P M, Davidson S, van der Veen A M H and Ent H 2017 On the traceability of gaseous reference materials Metrologia $\mathbf{5 4}$ L11

[18] van deer Veen A M H et al 2007 International comparison CCQM-P41 greenhouse gases. 1. Measurement capability Metrologia 408002

[19] van der Veen A M H et al 2007 International comparison CCQM-P41 greenhouse gases. 2. Direct comparison of primary standard gas mixtures Metrologia 4408003

[20] Flores E et al 2019 CCQM-K120 (carbon dioxide at background and urban level) Metrologia 5608001

[21] Wessel R M et al 2008 International comparison CCQM-K52: carbon dioxide in synthetic air Metrologia 4508011

[22] Flores E et al 2015 International comparison CCQM-K82: methane in air at ambient level (1800-2200) nmol mol Metrologia 5208001

[23] Lee J et al 2011 Final report on international comparison CCQM-K68: nitrous oxide in synthetic air Metrologia 4808004

[24] Flores E, Rhoderick G C, Viallon J, Moussay P, Choteau T, Gameson L, Guenther F R and Wielgosz R I 2015 Methane standards made in whole and synthetic air compared by cavity ring down spectroscopy and gas chromatography with flame ionization detection for atmospheric monitoring applications Anal. Chem. 87 3272-9

[25] ISO 61432001 Gas Analysis-Comparison Methods for Determining and Checking the Composition of Calibration Gas Mixtures (International Organisation for Standardisation)

[26] ISO 6142-1 2015 Gas Analysis-Preparation of Calibration Gas Mixtures-Part 1: Gravimetric Method for Class I Mixtures (International Organisation for Standardisation)

[27] van der Veen A M H and Hafner K 2014 Atomic weights in gas analysis Metrologia $\mathbf{5 1} 80$

[28] Possolo A, van der Veen A M H, Meija J and Hibbert D B 2018 Interpreting and propagating the uncertainty of the standard atomic weights (IUPAC Technical Report) Pure Appl. Chem. 90 395-424

[29] ISO 192292015 Gas Analysis-Purity Analysis and the Treatment of Purity Data (International Organisation for Standardisation)

[30] WMO 2018 19th WMO/IAEA Meeting on Carbon Dioxide, Other Greenhouse Gases and Related Tracers Measurement Techniques (GGMT-2017) (Geneva, Switzerland)

[31] Rhoderick G C, Kelley M, Miller W, Brailsford G and Possolo A 2016 Development of a southern oceanic air standard reference material Anal. Bioanal. Chem. 408 1159-69

[32] McNaught A D and Wilkinson A (eds) 1997 Compendium of Chemical Terminology (the "Gold Book") 2nd edn (Oxford: Blackwell) https://goldbook.iupac.org/html/C/C01214.html (Accessed: December 2018)

[33] Chen $\mathrm{H}$ et al $2010 \mathrm{High}$-accuracy continuous airborne measurements of greenhouse gases $\left(\mathrm{CO}_{2}\right.$ and $\left.\mathrm{CH}_{4}\right)$ using the cavity ring-down spectroscopy (CRDS) technique Atmos. Meas. Tech. 3 375-86

[34] Rella C W et al 2012 High accuracy measurements of dry mole fractions of carbon dioxide and methane in humid air Atmos. Meas. Tech. 6 837-60

[35] Nara H, Tanimoto H, Tohjima Y, Mukai H, Nojiri Y, Katsumata K and Rella C W 2012 Effect of air composition 
$\left(\mathrm{N}_{2}, \mathrm{O}_{2}, \mathrm{Ar}\right.$, and $\left.\mathrm{H}_{2} \mathrm{O}\right)$ on $\mathrm{CO}_{2}$ and $\mathrm{CH}_{4}$ measurement by wavelength-scanned cavity ring-down spectroscopy: calibration and measurement strategy Atmos. Meas. Tech. 5 2689-701

[36] Rhoderick G C 2013 The National Institute of Standards and Technology ambient level methane in air standard reference material historical record Anal. Bioanal. Chem. 405 369-75

[37] Rhoderick G C 2012 NIST gravimetrically prepared atmospheric level methane in dry air standards suite Anal. Chem. 84 3802-10

[38] Matsumoto N, Watanabe T, Maruyama M, Horimoto Y, Maeda T and Kato K 2004 Development of mass measurement equipment using an electronic masscomparator for gravimetric preparation of reference gas mixtures Metrologia 41178

[39] Leuenberger M C, Schibig M F and Nyfeler P 2014 Gas adsorption and desorption effects on cylinders and their importance for long-term gas records Atmos. Chem. Phys. Discuss. 14 19293-314

[40] Lee S, Kim M E, Oh S H and Kim J 2017 Determination of physical adsorption loss of primary standard gas mixtures in cylinders using cylinder-to-cylinder division Metrologia $54 \mathrm{~L} 26$

[41] Miller W R, Rhoderick G C and Guenther F R 2015 Investigating adsorption/desorption of carbon dioxide in aluminum compressed gas cylinders Anal. Chem. 87 1957-62

[42] Brewer P J, Brown R J C, Resner K V, Hill-Pearce R E, Worton D R, Allen N D C, Blakley K C, Benucci D and Ellison M R 2018 Influence of pressure on the composition of gaseous reference materials, analytical chemistry Anal. Chem. $903490-5$

[43] Atomic weights of the elements 2017 (www.ciaaw.org (Accessed: December 2018))

[44] van der Veen A M H et al 2000 International comparison CCQM-P23 gravimetric preparation of primary standard gas mixtures, $\mathrm{CO}$ in nitrogen

[45] Nieuwenkamp G and van der Veen A M 2006 Discrepancy in infrared measurement results of carbon monoxide in nitrogen mixtures due to variations of the ${ }^{13} \mathrm{C} /{ }^{12} \mathrm{C}$ isotope ratio Accred. Qual. Assur. 10 506-9

[46] Brailsford G 2012 16th WMO/IAEA Meeting of Experts on Carbon Dioxide, Other Greenhouse Gases and Related Measurement Techniques (GAW Report No. 206)

[47] Lee J Y, Yoo H S, Marti K, Moon D M, Lee J B and Kim J S 2006 Effect of carbon isotopic variations on measured $\mathrm{CO}_{2}$ abundances in reference gas mixtures J. Geophys. Res. 111 D05302

[48] Brewer P J, Brown R J C, Miller M N, Minarro M D, Murugan A, Milton M J T and Rhoderick G C 2014 Preparation and validation of fully synthetic standard gas mixtures with atmospheric isotopic composition for global $\mathrm{CO}_{2}$ and $\mathrm{CH}_{4}$ monitoring Anal. Chem. 86 1887-93

[49] Flores E, Viallon J, Moussay P, Griffith D W T and Wielgosz R I 2017 Calibration strategies for FTIR and other IRIS instruments for accurate $\delta^{13} \mathrm{C}$ and $\delta^{18} \mathrm{O}$ measurements of $\mathrm{CO}_{2}$ in air Anal. Chem. 89 3648-55

[50] Wen X F, Meng Y, Zhang X Y, Sun X M and Lee X 2013 Evaluating calibration strategies for isotope ratio infrared spectroscopy for atmospheric ${ }^{13} \mathrm{CO}_{2} /{ }^{12} \mathrm{CO}_{2}$ measurement Atmos. Meas. Tech. 6 1491-501

[51] 2017 Consultative Committee for amount of substance: metrology in chemistry and biology (CCQM) Report of the 23rd Meeting (Sèvres: The International Bureau of Weights and Measures) p 36

[52] Tans P P, Crotwell A M and Thoning K W 2017 Abundances of isotopologues and calibration of $\mathrm{CO}_{2}$ greenhouse gas measurements Atmos. Meas. Tech. 10 2669-85
[53] Brewer P J, Brown R J C, Tarasova O, Hall B, Rhoderick G and Wielgosz R 2018 SI traceability and scales for underpinning atmospheric monitoring of greenhouse gases Metrologia 55 S174

[54] WMO 2014 17th WMO/IAEA Meeting on Carbon Dioxide, Other Greenhouse Gases and Related Tracers Measurement Techniques (GGMT-2013) (Geneva, Switzerland)

[55] WMO 2016 18th WMO/IAEA Meeting on Carbon Dioxide, Other Greenhouse Gases and Related Tracers Measurement Techniques (GGMT-2015) (Geneva, Switzerland)

[56] Dlugokencky E J, Myers R C, Lang P M, Masarie K A, Crotwell A M, Thoning K W, Hall B D, Elkins J W and Steele L P 2005 Conversion of NOAA atmospheric dry air $\mathrm{CH}_{4}$ mole fractions to a gravimetrically prepared standard scale J. Geophys. Res. 110 D18306

[57] Hall B D, Dutton G S and Elkins J W 2007 The NOAA nitrous oxide standard scale for atmospheric observations J. Geophys. Res. 112 D09305

[58] Lim J S, Lee J, Moon D, Kim J S, Lee J D and Hall B D 2017 Gravimetric standard gas mixtures for global monitoring of atmospheric $\mathrm{SF}_{6}$ Anal. Chem. 89 12068-75

[59] Hall B D, Dutton G S, Mondeel D J, Nance J D, Rigby M, Butler J H, Moore F L, Hurst D F and Elkins J W 2011 Improving measurements of $\mathrm{SF}_{6}$ for the study of atmospheric transport and emissions Atmos. Meas. Tech. $42441-51$

[60] Kelley M E, Rhoderick G C and Guenther F R 2014 Development and verification of air balance gas primary standard for the measurement of nitrous oxide at atmospheric levels Anal. Chem. 86 4544-9

[61] Hall B D et al 2013 Results from the international halocarbons in air comparison experiment (IHALACE) Atmos. Meas. Tech. Discuss. 6 8021-69

[62] Krummel P B et al 2017 An update of comparisons of non- $\mathrm{CO}_{2}$ trace gas measurements between AGAGE and NOAA at common sites 19th WMO/IAEA GGMT Meeting (Dübendorf, Switzerland) www.wmo.int/pages/prog/ arep/gaw/documents/GGMT2017_T03_Krummel.pdf (Accessed: December 2018)

[63] Zhao C L, Tans P P and Thoning K W 1997 A high precision manometric system for absolute calibrations of $\mathrm{CO}_{2}$ in dry air J. Geophys. Res. 102 5885-94

[64] Keeling C D 1960 The concentration and isotopic abundance of carbon dioxide in the atmosphere Tellus 12 200-3

[65] Guenther P R 1978 Manometer Report I: Manometric Calibrations of Primary Reference Gases During 1969 and 1970 (SIO Reference Series) (La Jolla, CA: Scripps Institution of Oceanography)

[66] Guenther P R 1978 Manometer Report II: Manometric Calibrations of Primary Reference Gases and Internal Manometric Volume Calibrations During 1972 (SIO Reference Series) (La Jolla, CA: Scripps Institution of Oceanography)

[67] Guenther P R 1981 Manometer Report IV: Internal Manometric Volume Calibrations During 1974 (SIO Reference Series) (La Jolla, CA: Scripps Institution of Oceanography)

[68] Guenther P R and Keeling C D 1981 Manometer Report III: Manometric Calibrations of Primary $\mathrm{CO}_{2}$ Reference Gases During 1974 (SIO Reference Series) (La Jolla, CA: Scripps Institution of Oceanography)

[69] Keeling R F, Guenther P R Walker S and Moss D J 2016 Scripps Reference Gas Calibration System for Carbon Dioxide-in-Nitrogen and Carbon Dioxide-in-Air Standards: Revision of 2012 (Scripps $\mathrm{CO}_{2}$ Program) (La Jolla, CA: Scripps Institution of Oceanography)

[70] Keeling C D, Guenther P R and Moss D J 1986 Scripps reference gas calibration system for carbon dioxide-in-air 
standards: revision of 1985 WMO Technical Report No. 125 WMO

[71] Keeling C D, Bacastow R B, Guenther P R and Moss D J 1983 Scripps Reference Gas Calibrating System for Carbon Dioxide in Air Standards (Revision of 1982) (La Jolla, CA: Scripps Institution of Oceanography)

[72] Zhao C L and Tans P P 2006 Estimating uncertainty of the WMO mole fraction scale for carbon dioxide in air $J$. Geophys. Res. 111 D08S09

[73] Tans P P, Zhao C L and Kitzis D 2011 The WMO mole fraction scales for $\mathrm{CO}_{2}$ and other greenhouse gases, and uncertainty of the atmospheric measurements $15 \mathrm{th}$ WMO/ IAEA Meeting of Experts on Carbon Dioxide, Other Greenhouse Gases and Related Tracers Measurement Techniques (Geneva, Switzerland)

[74] Hall B, Kitzis D and Tans P P 2014 Recent analysis of the WMO $\mathrm{CO}_{2}$ primary standards 17 th WMO/IAEA Meeting on Carbon Dioxide, Other Greenhouse Gases and Related Tracers Measurement Techniques (GGMT-2013) (Geneva, Switzerland)

[75] WMO 2017 WMO Global Atmosphere Watch (GAW) Implementation Plan: 2016-2023 (Geneva, Switzerland: World Meteorological Organization)

[76] Zellweger C, Emmenegger L, Firdaus M, Hatakka J, Heimann M, Kozlova E, Spain T G, Steinbacher M, van der Schoot M V and Buchmann B 2016 Assessment of recent advances in measurement techniques for atmospheric carbon dioxide and methane observations Atmos. Meas. Tech. 9 4737-57

[77] NOAA 2018 WMO/IAEA Round Robin Comparison Experiment (Boulder, CO :National Oceanic and Atmospheric Administration)

[78] Brand W A, Coplen T B, Vogl J, Rosner M and Prohaska T 2014 Assessment of international reference materials for isotope-ratio analysis (IUPAC Technical Report) Pure Appl. Chem. 86 425-67

[79] Brand W A and Coplen T B 2012 Stable isotope deltas: tiny, yet robust signatures in nature Isot. Environ. Health Stud. 48 393-409

[80] Meija J et al 2016 Atomic weights of the elements 2013 (IUPAC Technical Report) Pure Appl. Chem. 88 265-91

[81] Reference Sheet for VSMOW2 and SLAP2 (available at https://nucleus.iaea.org/rpst/Documents/VSMOW2 SLAP2.pdf)

[82] Reference Sheet for IAEA-603 (available at https://nucleus. iaea.org/rpst/referenceproducts/referencematerials/Stable_ Isotopes/13C18and7Li/IA A-603/RM603_Reference Sheet_2016-08-16.pdf. 2016)

[83] Gröning M, van Duren M and Andreescu L 2007 Metrological characteristics of the conventional measurement scales for hydrogen and oxygen stable isotope amount ratios: the $\delta$-scales Combining and Reporting Analytical Results eds A Fajgelj, M Belli and U Sansone Proc. International Workshop on Combining and reporting analytical results: The role of traceability and uncertainty for comparing analytical results, (Rome, Italy, 6-8 March 2006) pp 62-72

[84] Hut G 1987 Consultants' Group Meeting on Stable Isotope Reference Samples for Geochemical and Hydrological Investigations (Vienna, Austria)

[85] Coplen T B, Brand W A, Gehre M, Gröning M, Meijer H A J, Toman B and Verkouteren R M 2006 New guidelines for $\delta^{13} \mathrm{C}$ measurements Anal. Chem. 78 2439-41

[86] Assonov S, Gröning M and Fajgelj A 2016 IAEA stable isotope reference materials: addressing the needs of atmospheric greenhouse gas monitoring 18th WMO/IAEA Meeting on Carbon Dioxide, Other Greenhouse Gases and Related Tracers Measurement Techniques (GGMT-2015) (GAW Report No. 229, WMO) pp 76-80
[87] Qi H, Coplen T B, Mroczkowski S J, Brand W A, Brandes L, Geilmann H and Schimmelmann A 2016 A new organic reference material, l-glutamic acid, USGS41a, for $\delta(13) \mathrm{C}$ and $\delta(15) \mathrm{N}$ measurements - a replacement for USGS41 Rapid Commun. Mass Spectrom. 30 859-66

[88] IUPAC 2018 Standard atomic weights of 14 chemical elements revised (press release)

[89] Ghosh P, Patecki M, Rothe M and Brand W A 2005 Rapid Commun. Mass Spectrom. 19 1097-119

[90] ISO 17034:2016 2016 General Requirements for the Competence of Reference Material Producers (International Organisation for Standardisation)

[91] Santrock J, Studley S A and Hayes J M 1985 Isotopic analyses based on the mass spectrum of carbon dioxide Anal. Chem. 57 1444-8

[92] Norgaard J V, Valkiers S, Van Nevel L, Vendelvo E, Papadakis I, Bréas O and Taylor P D P 2002 The international measurement evaluation programme, IMEP-8: carbon and oxygen isotope ratios in $\mathrm{CO}_{2}$ Anal. Bioanal. Chem. 374 1147-54

[93] Malinovsky D, Dunn P J H and Goenaga-Infante H 2013 Determination of absolute C-13/C-12 isotope amount ratios by MC-ICPMS using calibration with synthetic isotope mixtures J. Anal. At. Spectrom. 28 1760-71

[94] Russe K, Valkiers S and Taylor P D P 2004 Synthetic isotope mixtures for the calibration of isotope amount ratio measurements of carbon Int. J. Mass Spectrom. 235 255-62

[95] Valkiers S, Varlam M, Ruße K, Berglund M, Taylor P, Wang J, Milton M J T and Bièvre P D 2007 Preparation of synthetic isotope mixtures for the calibration of carbon and oxygen isotope ratio measurements (in carbon dioxide) to the SI internat J. Mass Spectrom. 264 10-21

[96] Koulikov S, Assonov S, Fajgelj A and Tans P 2018 Potential improvements aimed at high precision delta $\mathrm{C}-13$ isotopic ratio determinations in $\mathrm{CO}_{2}$ mixtures using optical absorption spectrometry Talanta 184 73-86

[97] Mukai H 2003 12th IAEA/WMO Meeting of $\mathrm{CO}_{2}$ Experts (Toronto, Canada)

[98] Ostrom N E et al 2018 Preliminary assessment of stable nitrogen and oxygen isotopic composition of USGS51 and USGS52 nitrous oxide reference gases and perspectives on calibration needs Rapid Commun. Mass Spectrom. 32 1207-14

[99] Verkouteren R M and Klinedinst D B 2004 NIST Special Publication 2016-149 (Washington, DC: US Government Printing Office) p 59

[100] Brand W A, Huang L, Mukai H, Chivulescu A, Richter J M and Rothe M 2009 How well do we know VPDB? Variability of $\delta^{13} \mathrm{C}$ and $\delta^{18} \mathrm{O}$ in $\mathrm{CO}_{2}$ generated from NBS19-calcite Rapid Commun. Mass Spectrom. 23 915-26

[101] Mukai H, Nakazawa T, Brand W A, Huang L, Levin I, Allison C, White J W C, Leuenberger M and Assonov S A 2007 Proc. of the 13th IAEA/WMO Meeting of $\mathrm{CO}_{2}$ Experts (Boulder, September 2005) ed J B Miller (WMOGAW Report 168) p 41 (values for RMs 8562-8564 have been recently updated, https://www-s.nist.gov/srmors)

[102] McCrea J M 1950 On the isotopic chemistry of carbonates and a paleotemperature scale J. Chem. Phys. 18 849-57

[103] Wendeberg M, Richter J M, Rothe M and Brand W A $2011 \delta^{18} \mathrm{O}$ anchoring to VPDB: calcite digestion with ${ }^{18} \mathrm{O}$-adjusted ortho-phosphoric acid Rapid Commun. Mass Spectrom. 25 851-60

[104] Wendeberg M, Richter J M, Rothe M and Brand W A 2013 Jena reference air set (JRAS): a multi-point scale anchor for isotope measurements of $\mathrm{CO}_{2}$ in air Atmos. Meas. Tech. 6 817-22 
[105] Lowe D C, Brenninkmeijer C A M, Tyler S C and Dlugkencky E J 1991 Determination of the isotopic composition of atmospheric methane and its application in the antarctic J. Geophys. Res. $9615455-67$

[106] Umezawa T et al 2018 Interlaboratory comparison of $\delta^{13} \mathrm{C}$ and $\delta \mathrm{D}$ measurements of atmospheric $\mathrm{CH}_{4}$ for combined use of data sets from different laboratories Atmos. Meas. Tech. 11 1207-31

[107] Sperlich P, Uitslag N A M, Richter J M, Rothe M, Geilmann H, van der Veen C, Röckmann T, Blunier T and Brand W A 2016 Development and evaluation of a suite of isotope reference gases for methane in air Atmos. Meas. Tech. $93717-37$

[108] Brand W A, Rothe M, Sperlich P, Strube M and Wendeberg M 2016 Automated simultaneous measurement of the $\delta^{13} \mathrm{C}$ and $\delta^{2} \mathrm{H}$ values of methane and the $\delta^{13} \mathrm{C}$ and $\delta^{18} \mathrm{O}$ values of carbon dioxide in flask air samples using a new multi cryo-trap/gas chromatography/ isotope ratio mass spectrometry system Rapid Commun. Mass Spectrom. 30 1523-39

[109] Bergamaschi P, Schupp M and Harris G W 1994 Highprecision direct measurements of ${ }^{13} \mathrm{CH}_{4} /{ }^{12} \mathrm{CH}_{4}$ and ${ }^{12} \mathrm{CH}_{3} \mathrm{D} /{ }^{12} \mathrm{CH}_{4}$ ratios in atmospheric methane sources by means of a long-path tunable diode laser absorption spectrometer Appl. Opt. 33 7704-16

[110] Toyoda S and Yoshida N 1999 Determination of nitrogen isotopomers of nitrous oxide on a modified isotope ratio mass spectrometer Anal. Chem. 71 4711-8

[111] Mohn J et al 2016 Reassessment of the $\mathrm{NH}_{4} \mathrm{NO}_{3}$ thermal decomposition technique for calibration of the $\mathrm{N}_{2} \mathrm{O}$ isotopic composition Rapid Commun. Mass Spectrom. 30 2487-96

[112] Westley M B, Popp B N and Rust T M 2007 The calibration of the intramolecular nitrogen isotope distribution in nitrous oxide measured by isotope ratio mass spectrometry Rapid Commun. Mass Spectrom. 21 391-405

[113] Mohn J et al 2014 Interlaboratory assessment of nitrous oxide isotopomer analysis by isotope ratio mass spectrometry and laser spectroscopy: current status and perspectives Rapid Commun. Mass Spectrom. 28 1995-2007

[114] www.euramet.org/research-innovation/ (Accessed: December 2018)

[115] Lopez M, Schmidt M, Ramonet M, Vonne J-L, Colomb A, Kazan V, Laj P and Pichon J-M 2015 Three years of semicontinous greenhouse gas measurements at the Puy de Dôme station (central France) Atmos. Meas. Tech. $83941-58$

[116] Schmidt M et al 2014 High-precision quasi-continuous atmospheric greenhouse gas measurements at Trainou tower (Orléans forest, France) Atmos. Meas. Tech. $72283-96$

[117] Weiss R F 1981 Determinations of carbon dioxide and methane by dual catalyst flame ionization chromatography and nitrous oxide by electron capture chromatography J. Chroma Sci. 19 611-6

[118] Worthy D E J, Platt A, Kessler R, Ernst M and Racki S 2003 Measurement Procedures and Data Quality, Canadian Baseline Program; Summary of progress to 2002, Meteorological Service of Canada, Quebec, Canada pp 97-120

[119] Vermeulen A T, Hensen A, Popa M E, van den Bulk W C M and Jongejan P A C 2011 Greenhouse gas observations from Cabauw Tall Tower (1992-2010) Atmos. Meas. Tech. 4 617-44

[120] Fehsenfeld F C 1981 Selective electron-capture sensitization Electron Capture: Theory and Practice in Chromatography ed A Zlatkis and C F Poole (New York: Elsevier) pp 69-90
[121] Andrews A E et al $2014 \mathrm{CO}_{2}, \mathrm{CO}$, and $\mathrm{CH}_{4}$ measurements from tall towers in the NOAA earth system research laboratory's global greenhouse gas reference network: instrumentation, uncertainty analysis, and recommendations for future high-accuracy greenhouse gas monitoring efforts Atmos. Meas. Tech. 7 647-87

[122] Griffith D W T, Keeling C D, Adams J A, Guenther P R and Bacastow R B 1982 Calculations of carrier gas effects in non-dispersive infra-red analysers. II. Comparisons with experiment Tellus 34 376-84

[123] Takahashi T, Weaver M O and Prince L A 1976 The effect of oxygen in the carrier gas for infrared gas analysis of $\mathrm{CO}_{2}$ J. Geophys. Res. 81 3736-8

[124] Tohjima Y, Katsumata K, Morino I, Mukai H, Machida T, Akama I, Amari T and Tsunogai U 2009 Theoretical and experimental evaluation of the isotope effect of NDIR analyzer on atmospheric $\mathrm{CO}_{2}$ measurement $J$. Geophys. Res. 114 D13302

[125] Nier A O 1947 A mass spectrometer for isotope and gas analysis Rev. Sci. Instrum. 18 398-411

[126] Prohaska T, Irrgeher J, Zitek A and Jakubowski N 2015 Sector Field Mass Spectrometry for Elemental and Isotopic Analysis (Cambridge: The Royal Society of Chemistry) p 615

[127] Brand W A 2004 Chapter 38-mass spectrometer hardware for analyzing stable isotope ratios Handbook of Stable Isotope Analytical Techniques ed P A de Groot (Amsterdam: Elsevier) pp 835-56

[128] Jochmann M A and Schmidt T C 2012 Compound-Specific Stable Isotope Analysis (Cambridge: The Royal Society of Chemistry)

[129] Vestal M L 2001 Methods of ion generation Chem. Rev. $101361-75$

[130] Wendeberg M and Brand W A 2010 Isotope ratio mass spectrometry (IRMS): light elements (C, H, O, N, S) Elemental and Isotope Ratio Mass Spectrometry ed D Beauchemin and D E Matthews (Amsterdam: Elsevier)

[131] McKinney C R, McCrea J M, Epstein S, Allen H A and Urey H C 1950 Improvements in mass spectrometers for the measurement of small differences in isotope abundance ratios Rev. Sci. Instrum. 21 724-30

[132] Werner R A and Brand W A 2001 Referencing strategies and techniques in stable isotope ratio analysis Rapid Commun. Mass Spectrom. 15 501-19

[133] Preston T and Owens N J P 1983 Interfacing an automatic elemental analyzer with an isotope ratio mass spectrometer-the potential for fully automated total nitrogen and nitrogen-15 analysis Analyst 108 971-7

[134] Werner R A, Bruch B A and Brand W A 1999 ConFlo III-an interface for high precision $\delta^{13} \mathrm{C}$ and $\delta^{15} \mathrm{~N}$ analysis with an extended dynamic range Rapid Commun. Mass Spectrom. 13 1237-41

[135] Hilkert A W, Kouthitt C F, Schlüter H J and Brand W A 1999 Isotope ratio monitoring gas chromatography/mass spectrometry of $\mathrm{D} / \mathrm{H}$ by high temperature conversion isotope ratio mass spectrometry Rapid Commun. Mass Spectrom. 13 1226-30

[136] Matthews D E and Hayes J M 1978 Isotope-ratio-monitoring gas chromatography-mass spectrometry Anal. Chem. 50 1465-73

[137] Cerling T E, Barnette J E, Bowen G J, Chesson L A, Ehleringer J R, Remien C H, Shea P, Tipple B J and West J B 2016 Forensic stable isotope biogeochemistry Annu. Rev. Earth Planet. Sci. 44 175-206

[138] Sharp Z 2007 Principles of Stable Isotope Geochemistry 1st edn (Upper Saddle River, NJ: Pearson) p 344

[139] Eiler J M and Schauble E $2004{ }^{18} \mathrm{O}^{13} \mathrm{C}^{16} \mathrm{O}$ in Earth's atmosphere Geochim. Cosmochim. Acta 68 4767-77 
[140] Eiler J M, Clog M, Magyar P, Piasecki A, Sessions A, Stolper D, Deerberg M, Schlueter H-J and Schwieters J 2013 A high-resolution gas-source isotope ratio mass spectrometer Int. J. Mass Spectrom. 335 45-56

[141] Young E D, Rumble D, Freedman P and Mills M 2016 A large-radius high-mass-resolution multiple-collector isotope ratio mass spectrometer for analysis of rare isotopologues of $\mathrm{O}_{2}, \mathrm{~N}_{2}, \mathrm{CH}_{4}$ and other gases Int. J. Mass Spectrom. 401 1-10

[142] Okeefe A and Deacon D AG 1988 Cavity ring-down optical spectrometer for absorption-measurements using pulsed laser sources Rev. Sci. Instrum. 59 2544-51

[143] Sappey A D, Hill E S, Settersten T and Linne M A 1998 Fixed-frequency cavity ringdown diagnostic for atmospheric particulate matter Opt. Lett. 23 954-6

[144] Smith J D and Atkinson D B 2001 A portable pulsed cavity ring-down transmissometer for measurement of the optical extinction of the atmospheric aerosol Analyst 126 1216-20

[145] Snyder K L and Zare R N 2003 Cavity ring-down spectroscopy as a detector for liquid chromatography Anal. Chem. 75 3086-91

[146] Ball S M and Jones R L 2003 Broad-band cavity ring-down spectroscopy Chem. Rev. 103 5239-62

[147] Berden G E R and Engeln R 2009 Cavity Ring-Down Spectroscopy: Techniques and Applications (Oxford: Blackwell Publishing Ltd)

[148] Wheeler M D, Newman S M, Orr-Ewing A J and Ashfold N R 1998 Cavity ring-down spectroscopy J. Chem. Soc. 94 337-51

[149] Hodges J T, Looney J P and vanZee R D 1996 Laser bandwidth effects in quantitative cavity ring-down spectroscopy Appl. Opt. 35 4112-6

[150] Romanini D and Lehmann K K 1993 Ring-down cavity absorption-spectroscopy of the very weak $\mathrm{HCN}$ overtone bands with 6,7, and 8 stretching quanta J. Chem. Phys. 99 6287-301

[151] Zalicki P and Zare R N 1995 Cavity ring-down spectroscopy for quantitative absorption-measurements J. Chem. Phys. 102 2708-17

[152] Brown S S, Stark H and Ravishankara A R 2002 Cavity ringdown spectroscopy for atmospheric trace gas detection: application to the nitrate radical $\left(\mathrm{NO}_{3}\right)$ Appl. Phys. B 75 173-82

[153] Kosterev A A, Malinovsky A L, Tittel F K, Gmachl C, Capasso F, Sivco D L, Baillargeon J N, Hutchinson A L and Cho A Y 2001 Cavity ringdown spectroscopic detection of nitric oxide with a continuous-wave quantumcascade laser Appl. Opt. 40 5522-9

[154] Paldus B A, Harb C C, Spence T G, Wilke B, Xie J, Harris J S and Zare R N 1998 Cavity-locked ring-down spectroscopy J. Appl. Phys. 83 3991-7

[155] Romanini D, Kachanov A A, Sadeghi N and Stoeckel F 1997 CW cavity ring down spectroscopy Chem. Phys. Lett. 264 316-22

[156] Hodges J T, Layer H P, Miller W W and Scace G E 2004 Frequency-stabilized single-mode cavity ring-down apparatus for high-resolution absorption spectroscopy Rev. Sci. Instrum. 75 849-63

[157] Long D A, Cygan A, van Zee R D, Okumura M, Miller C E, Lisak D and Hodges J T 2012 Frequency-stabilized cavity ring-down spectroscopy Chem. Phys. Lett. $5361-8$

[158] Long D A, Gameson L, Truong G W, Bielska K, Cygan A, Hodges J T, Whetstone J R and van Zee R D 2013 The Effects of variations in buffer gas mixing ratios on commercial carbon dioxide cavity ring-down spectroscopy sensors J. Atmos. Ocean. Technol. 30 2604-9

[159] Odintsova T A, Fasci E, Moretti L, Zak E J, Polyansky O L, Tennyson J, Gianfrani L and Castrillo A 2017 Highly accurate intensity factors of pure $\mathrm{CO}_{2}$ lines near $2 \mu \mathrm{m}$ J. Chem. Phys. 146244309

[160] Sironneau V T and Hodges J T 2015 Line shapes, positions and intensities of water transitions near $1.28 \mu \mathrm{m} J$. Quant. Spectrosc. Radiat. Transfer 152 1-15

[161] Tashkun S A, Perevalov V I, Gamache R R and Lamouroux J 2015 CDSD-296 high resolution carbon dioxide spectroscopic databank: version for atmospheric applications J. Quant. Spectrosc. Radiat. Transfer $15245-73$

[162] Huang X C, Schwenke D W, Freedman R S and Lee T J 2017 Ames-2016-line lists for 13 isotopologues of $\mathrm{CO}_{2}$ : updates, consistency, and remaining issues J. Quant. Spectrosc. Radiat. Transfer $203224-41$

[163] Zak E, Tennyson J, Polyansky O L, Lodi L, Zobov N, Tashkun S A and Perevalov V I 2016 A room temperature $\mathrm{CO}_{2}$ line list with $a b$ initio computed intensities J. Quant. Spectrosc. Radiat. Transfer 177 31-42

[164] Lisak D, Havey D K and Hodges J T 2009 Spectroscopic line parameters of water vapor for rotation-vibration transitions near $7180 \mathrm{~cm}^{-1}$ Phys. Rev. A 79052507

[165] Polyansky O L, Bielska K, Ghysels M, Lodi L, Zobov N F, Hodges J T and Tennyson J 2015 High-accuracy $\mathrm{CO}_{2}$ line intensities determined from theory and experiment Phys. Rev. Lett. 114243001

[166] Yi H M, Liu Q, Gameson L, Fleisher A J and Hodges J T 2018 High-accuracy $\left(\mathrm{CO}_{2}\right)-\mathrm{C}-12-\mathrm{O}-16$-line intensities in the $2 \mu \mathrm{m}$ wavelength region measured by frequencystabilized cavity ring-down spectroscopy J. Quant. Spectrosc. Radiat. Transfer 206 367-77

[167] Tennyson J et al 2014 Recommended isolated-line profile for representing high-resolution spectroscopic transitions (IUPAC Technical Report) Pure Appl. Chem. 86 1931-43

[168] Wojtewicz S, Stec K, Maslowski P, Cygan A, Lisak D, Trawinski R S and Ciurylo R 2013 Low pressure lineshape study of self-broadened CO transitions in the $(3 \leftarrow 0)$ band J. Quant. Spectrosc. Radiat. Transfer 130 191-200

[169] Pogany A, Ott O, Werhahn O and Ebert V 2013 Towards traceability in $\mathrm{CO}_{2}$ line strength measurements by TDLAS at $2.7 \mu \mathrm{m}$ J. Quant. Spectrosc. Radiat. Transfer 130 147-57

[170] Wubbeler G, Padilla Viquez G J, Jousten K, Werhahn O and Elster C 2011 Comparison and assessment of procedures for calculating the $\mathrm{R}(12)$ line strength of the $\mathrm{nu}(1)+2$ $\mathrm{nu}(2)+\mathrm{nu}(3)$ band of $\mathrm{CO}_{2}$ J. Chem. Phys. 135204304

[171] Gordon I E et al 2017 The HITRAN2016 molecular spectroscopic database J. Quant. Spectrosc. Radiat. Transfer 203 3-69

[172] Baer D S, Paul J B, Gupta M and O'Keefe A 2002 Sensitive absorption measurements in the near-infrared region using off-axis integrated-cavity-output spectroscopy Appl. Phys. B 75 261-5

[173] O'Keefe A 1998 Integrated cavity output analysis of ultraweak absorption Chem. Phys. Lett. 293 331-6

[174] O'Keefe A, Scherer J J and Paul J B 1999 CW integrated cavity output spectroscopy Chem. Phys. Lett. 307 343-9

[175] Engel G S, Drisdell W S, Keutsch F N, Moyer E J and Anderson J G 2006 Ultrasensitive near-infrared integrated cavity output spectroscopy technique for detection of $\mathrm{CO}$ at $1.57 \mu \mathrm{m}$ : new sensitivity limits for absorption measurements in passive optical cavities Appl. Opt. 45 9221-9

[176] Gulzow W, Rehder G, Schneider B, van Deimling J S and Sadkowiak B 2011 A new method for continuous measurement of methane and carbon dioxide in surface waters using off-axis integrated cavity output spectroscopy (ICOS): an example from the Baltic Sea Limnol. Oceanogr. 9 176-84 
[177] Kerstel E R T, Gagliardi G, Gianfrani L, Meijer H A J, van Tright $R$ and Ramaker R 2002 Determination of the $\mathrm{H}-2 / \mathrm{H}-1, \mathrm{O}-17 / \mathrm{O}-16$, and $\mathrm{O}-18 / \mathrm{O}-16$ isotope ratios in water by means of tunable diode laser spectroscopy at 1.39 $\mu \mathrm{m}$ Spectrochim. Acta A $\mathbf{5 8} 2389-96$

[178] Moyer E J, Sayres D S, Engel G S, St Clair J M, Keutsch F N, Allen N T, Kroll J H and Anderson J G 2008 Design considerations in high-sensitivity off-axis integrated cavity output spectroscopy Appl. Phys. B 92 467-74

[179] Hendriks D M D, Dolman A J, van der Molen M K and van Huissteden J 2008 A compact and stable eddy covariance set-up for methane measurements using off-axis integrated cavity output spectroscopy Atmos. Chem. Phys. 8 431-43

[180] Le L D, Tate J D, Seasholtz M B, Gupta M, Owano T, Baer D, Knittel T, Cowie A and Zhu J 2008 Development of a rapid on-line acetylene sensor for industrial hydrogenation reactor optimization using off-axis integrated cavity output spectroscopy Appl. Spectrosc. 62 59-65

[181] Leen J B, Yu X-Y, Gupta M, Baer D S, Hubbe J M, Kluzekm C D, Tomlinson J M and Hubbell M R 2013 Fast in situ airborne measurement of ammonia using a midinfrared off-axis ICOS spectrometer Environ. Sci. Technol. 47 10446-53

[182] Ebert V, Hemberger R, Meienburg W and Wolfrum J 1993 In situ gas analysis with infrared lasers Ber. Bunsenges. Phys. Chem. 97 1527-34

[183] Dreier T, Ebert V and Schulz C 2011 Laser-Based Combustion Diagnostics in Encyclopaedia of Analytical Chemistry 2nd edn, ed R A Meyers and J Wiley (Chichester: Wiley)

[184] Werle P, Slemr F, Maurer K, Kormann R, Mücke R and Jänker B 2002 Near- and mid-infrared laser-optical sensors for gas analysis Opt. Lasers Eng. 37 101-14

[185] Nelson D D, Shorter J H, McManus J B and Zahniser M S 2002 Sub-part-per-billion detection of nitric oxide in air using a thermoelectrically cooled mid-infrared quantum cascade laser spectrometer Appl. Phys. B $75343-50$

[186] Tuzson B, Zeeman M J, Zahniser M S and Emmenegger L 2008 Quantum cascade laser based spectrometer for in situ stable carbon dioxide isotope measurements Infrared Phys. Technol. 51 198-206

[187] Mantz A W 1994 A review of the applications of tunable diode laser spectroscopy at high sensitivity Microchem. $J$. 50 351-64

[188] Lee P S and Majkowski R F 1986 High resolution infrared diode laser spectroscopy for isotope analysismeasurement of isotopic carbon monoxide Appl. Phys. Lett. 48 619-21

[189] Becker J F, Sauke T B and Loewenstein M 1992 Stable isotope analysis using tunable diode laser spectroscopy Appl. Opt. 31 1921-7

[190] Wahlen M and Yoshinari T 1985 Oxygen isotope ratios in $\mathrm{N}_{2} \mathrm{O}$ from different environments Nature 313 780-2

[191] Lamb K D, Clouser B W, Bolot M, Sarkozy L, Ebert V, Saathoff H, Möhler O and Moyer E J 2017 Laboratory measurements of $\mathrm{HDO} / \mathrm{H}_{2} \mathrm{O}$ isotopic fractionation during ice deposition in simulated cirrus clouds Proc. Natl Acad. Sci. USA 114 5612-7

[192] Kühnreich B, Wagner S, Habig J C, Saathoff H, Moyer E J and Ebert V 2014 Open-path TDLAS for in situ detection of water isotopes in ice clouds down to $190 \mathrm{~K}$ Optics InfoBase Conf. Papers

[193] Nelson D D, McManus J B, Herndon S C, Zahniser M S, Tuzson B and Emmenegger L 2008 New method for isotopic ratio measurements of atmospheric carbon dioxide using a $4.3 \mathrm{~mm}$ pulsed quantum cascade laser Appl. Phys. B 90 301-9

[194] Tuzson B, Mohn J, Zeeman M J, Werner R A, Eugster W, Zahniser M S, Nelson D D, McManus J B and Emmenegger L 2008 High precision and continuous field measurements of $\delta^{13} \mathrm{C}$ and $\delta^{18} \mathrm{O}$ in carbon dioxide with a cryogen-free QCLAS Appl. Phys. B 92 451-8

[195] Mohn J, Tuzson B, Manninen A, Yoshida N, Toyoda S, Brand W A and Emmenegger L 2012 Site selective realtime measurements of atmospheric $\mathrm{N}_{2} \mathrm{O}$ isotopomers by laser spectroscopy Atmos. Meas. Technol. 5 1601-9

[196] Waechter H, Mohn J, Tuzson B, Emmenegger L and Sigrist M W 2008 Determination of $\mathrm{N}_{2} \mathrm{O}$ isotopomers with quantum cascade laser-based absorption spectroscopy $O p t$. Express 16 9239-44

[197] Eyer S et al 2016 Real-time analysis of $\delta^{13} \mathrm{C}$ - and $\delta \mathrm{D}-\mathrm{CH}_{4}$ in ambient methane with laser spectroscopy: method development and first inter-comparison results Atmos. Meas. Technol. $9263-80$

[198] Kantnerová K, Tuzson B, Emmenegger L, Bernasconi S M and Mohn J 2018 Site-specific analysis of $\mathrm{N}_{2} \mathrm{O}$ clumped isotopic species by laser spectroscopy Int. Symp. of Isotopomers 2018 (ISI2018) (Lousiana State University, Baton Rouge, USA)

[199] Ono S, Wang D T, Gruen D S, Lollar B S, Zahniser M S, McManus B J and Nelson D D 2014 Measurement of a doubly substituted methane isotopologue, ${ }^{13} \mathrm{CH}_{3} \mathrm{D}$, by tunable infrared laser direct absorption spectroscopy Anal. Chem. 86 6487-94

[200] Mohn J, Guggenheim C, Tuzson B, Vollmer M K, Toyoda S, Yoshida $\mathrm{N}$ and Emmenegger L 2010 A liquid nitrogen-free preconcentration unit for measurements of ambient $\mathrm{N}_{2} \mathrm{O}$ isotopomers by QCLAS Atmos. Meas. Technol. 3 609-18

[201] Capasso F, Gmachl C, Sivco D L and Cho A Y 2002 Quantum cascade lasers Phys. Today 55 34-9

[202] Faist J, Capasso F, Sivco D L, Sirtori C, Hutchinson A L and Cho A Y 1994 Quantum cascade laser Science 264 553-6

[203] Vurgaftman I, Weih R, Kamp M, Meyer J R, Canedy C L, Kim C S, Kim M, Bewley W W, Merritt C D and Abell J 2015 Interband cascade lasers J. Phys. D: Appl. Phys. 48123001

[204] Bewley W W, Canedy C L, Kim C S, Kim M, Merritt C D, Abell J, Vurgaftman I and Meyer J R 2012 Continuouswave interband cascade lasers operating above room temperature at $\lambda=4.7-5.6 \mu \mathrm{m}$ Opt. Express $203235-40$

[205] Bewley W W, Kim C S, Kim M, Merritt C D, Canedy C L, Vurgaftman I, Abell J and Meyer J R 2011 A new generation of interband cascade lasers AIP Conf. Proc. 1416 46-8

[206] Zeller W, Naehle L, Fuchs P, Gerschuetz F, Hildebrandt L and Koeth J 2010 DFB lasers between $760 \mathrm{~nm}$ and $16 \mu \mathrm{m}$ for sensing applications Sensors 10 2492-510

[207] Eugster W, Zeyer K, Zeeman M, Michna P, Zingg A, Buchmann N and Emmenegger L 2007 Methodical study of nitrous oxide eddy covariance measurements using quantum cascade laser spectrometry over a Swiss forest Biogeosciences 4 927-39

[208] Neftel A, Ammann C, Fischer C, Spirig C, Conen F, Emmenegger L, Tuzson B and Wahlen S $2010 \mathrm{~N}_{2} \mathrm{O}$ exchange over managed grassland: application of a quantum cascade laser spectrometer for micrometeorological flux measurements Agric. Forest Meteorol. $150775-85$

[209] Tuzson B, Hiller R V, Zeyer K, Eugster W, Neftel A, Ammann $\mathrm{C}$ and Emmenegger L 2010 Field intercomparison of two optical analyzers for $\mathrm{CH}_{4}$ eddy covariance flux measurements Atmos. Meas. Tech. 3 1519-31 
[210] Witzel O, Klein A, Meffert C, Wagner S, Kaiser S, Schulz C and Ebert V 2013 VCSEL-based high-speed TDLAS for in-cylinder water vapor concentration measurements in IC engines Opt. Express 21 19951-65

[211] Witzel O, Klein A, Wagner S, Meffert C, Schulz C and Ebert V 2012 High-speed tunable diode laser absorption spectroscopy for sampling-free in-cylinder water vapor concentration measurements in an optical IC engine Appl. Phys. B 109 521-32

[212] Ebert V and Wolfrum J 2001 Absorption Spectroscopy in Optical Measurements- Techniques and Applications (Heat and Mass Transfer) 2nd edn, ed F Mayinger and O Feldmann (Heidelberg: Springer) pp 227-65

[213] Ebert V, Teichert H, Giesemann C, Saathoff H and Schuraff U 2005 Fiber-coupled in situ-laser absorp-tion spectrometer for the selective detection of water vapor traces down to the ppb-level Tech. Mess. 72 23-30

[214] Pogany A, Klein A and Ebert V 2015 Measurement and validation of water vapor line strengths in the 1.4-2.7 $\mu \mathrm{m}$ range by high sensitivity TDLAS J. Quant. Spectrosc. Radiat. Transfer 165 108-22

[215] Schulz C, Dreizler A, Ebert V and Wolfrum J 2007 Combustion Diagnostics in Springer Handbook of Experimental Fluid Dynamics ed C Tropea et al (Berlin: Springer) pp 1241-316

[216] Awtry A R, Fisher B T, Moffatt R A, Ebert V and Fleming J W 2006 Simultaneous diode laser sased in situ quantification of oxygen, carbon monoxide, water vapor, and liquid water in a dense water mist environment Proc. Combust. Inst. 31 799-806

[217] Ebert V, Fernholz T, Giesemann C, Pitz H, Teichert H, Wolfrum J and Jaritz H 2000 Simultaneous diode-laserbased in situ-detection of multiple species and temperature in a gas-fired power-plant Proc. Combust. Inst. 28 423-30

[218] Jágerská J et al 2015 Simultaneous measurement of NO and $\mathrm{NO}_{2}$ using a dual-wavelength quantum cascade laser Proc. Advanced Photonics 2015 p SeT2D.5

[219] Kapsalidis F, Shahmohammadi M, Süess M J, Wolf J M, Gini E, Beck M, Hundt M, Tuzson B, Emmenegger L and Faist J 2018 Dual-wavelength DFB quantum cascade lasers: sources for multi-species trace gas spectroscopy Appl. Phys. B 124107

[220] Teichert H, Fernholz T and Ebert V 2003 In situ measurement of $\mathrm{CO}, \mathrm{H}_{2} \mathrm{O}$ and gas temperature in a lignitefired power-plant Appl. Opt. 42 2043-51

[221] Ebert V and Fleming J W 2007 Optical oxygen sensors using tunable diode laser spectroscopy: application to harsh reactive processes IEEE SENSORS pp 616-9

[222] Fernholz T, Teichert H and Ebert V 2002 Digital phasesensitive detection for in situ diode laser spectroscopy under rapidly changing transmission conditions Appl. Phys. B 75 229-36

[223] Skrotzki J, Habig J and Ebert V 2013 Integrative fitting of absorption line profiles with high accuracy, robust-ness, and speed Appl. Phys. B 116 1-14

[224] Vogel P and Ebert V 2001 Near shot noise detection of oxygen in the A-band with vertical-cavity-surface-emitting lasers Appl. Phys. B 72 127-35

[225] Klein A, Witzel O and Ebert V 2014 Rapidly time division multiplexed direct absorption- and wavelength modulation spectroscopy Sensors 14 21497-513

[226] White J U 1942 Long optical path of large aperture J. Opt. Soc. Am. 32 285-8

[227] Herriott D R and Schulte H J 1965 Folded optical delay lines Appl. Opt. 4 883-9

[228] McManus J B, Kebabian P L and Zahniser M S 1995 Astigmatic mirror multi-pass absorption cells for longpath-length spectroscopy Appl. Opt. 34 3336-48
[229] Gurlit W, Burrows J P, Zimmermann R, Platt U, Giesemann C, Wolfrum J and Ebert V 2005 Light-weight diode laser dpectrometer 'CHILD' for balloon-borne measurements of water vapor and methane Appl. Opt. 44 91-102

[230] Kühnreich B, Höh M, Wagner S and Ebert V 2016 Directly single-mode fibre-coupled miniature white-cell for laser absorption spectroscopy Rev. Sci. Instrum. 87023111

[231] Graf M, Emmenegger L and Tuzson B 2018 Compact, circular, and optically stable multipass cell for mobile laser absorption spectroscopy Opt. Lett. 43 2434-7

[232] Tuzson B, Mangold M, Looser H, Manninen A and Emmenegger L 2013 Compact multipass optical cell for laser spectroscopy Opt. Lett. 38 257-9

[233] Buchholz B, Kallweit S and Ebert V 2017 SEALDH-II-an autonomous, holistically controlled, first principles TDLAS hygrometer for field and airborne applications: design-setup-accuracy/stability stress test Sensors $\mathbf{1 7} 68$

[234] Nwaboh J, Pratzler S, Werhahn O and Ebert V 2016 Tunable diode laser absorption spectroscopy sensor for calibration free humidity measurements in pure methane and low $\mathrm{CO}_{2}$ natural gas Appl. Spectrosc. 71 888-900

[235] Viallon J, Moussay P, Norris J E, Guenther F R and Wielgosz R I 2006 A study of systematic biases and measurement uncertainties in ozone mole fraction measurements with the NIST Standard reference photometer Metrologia 43 441-50

[236] Martin P and Puerta H 1981 Generalized Lorentzian approximations for the Voigt line shape Appl. Opt. 20 259-63

[237] Ebert V, Brunzendorf J and Werwein V 2013 Spectral reference line data for atmospheric monitoring Proc. of the EUMETRISPEC Workshop Held at Wolfenbüttel Castle and PTB Braunschweig (15-16 November 2012) (PTB-Bericht Chemische Physik)

[238] Pogány A, Werhahn O and Ebert V 2016 High-accuracy ammonia line intensity measurements at $1.5 \mu \mathrm{m}$ Imaging and Applied Optics 2016

[239] Nwaboh J, Werhahn O and Ebert V 2014 Line strength and collisional broadening coefficients of $\mathrm{H}_{2} \mathrm{O}$ at $2.7 \mu \mathrm{m}$ for natural gas quality assurance applications Mol. Phys. 112 2451-61

[240] Ortwein P, Woiwode W, Wagner S, Gisi M and Ebert V 2010 Laser-based measurements of line strength, self and pressure broadening coefficients of the $\mathrm{H}_{35} \mathrm{Cl} \mathrm{R}(3)$ absorption line in the first overtone region for pressures up to $1 \mathrm{MPa}$ Appl. Phys. B $100341-7$

[241] Li G, Serdyukov A, Gisi M, Werhahn O and Ebert V 2015 FTIR based measurements of the self-broadening and self-shift coefficients as well as line strength in the first overtone band of $\mathrm{HCl}$ at $1.76 \mu \mathrm{m}$ J. Quant. Spectrosc. Radiat. Transfer 165 76-87

[242] Werwein V, Bruzendorf J, Li G, Serdyukov A, Werhahn O and Ebert V 2017 High-resolution fourier transform measurements of line strengths in the 0002-0000 main isotopo-logue band of nitrous oxide Appl. Opt. 56 E99-105

[243] Werwein V, Brunzendorf J, Serdyukov A, Werhahn O and Ebert V 2016 First measurements of nitrous oxide selfbroadening and self-shift coefficients in the 0002-0000 band at $2.26 \mu \mathrm{m}$ using high resolution Fourier transform spectroscopy J. Mol. Spectrosc. 323 28-42

[244] Nwaboh J A, Werhahn O, Ortwein P, Schiel D and Ebert V 2013 Laser-spectrometric gas analysis: $\mathrm{CO}_{2}$-TDLAS at 2 um Meas. Sci. Technol. 24 15202-12

[245] Werhahn O, Brunzendorf J, Nwaboh J, Serdyukov A, Werwein V and Ebert V 2014 Spectral reference line data relevant to remote sensing applications-a review 
and outline of the EUMETRISPEC project Proc. SPIE $924292420 \mathrm{D}$

[246] Nwaboh J, Witzel O, Pogany A, Werhahn O and Ebert V 2014 Optical path length calibration: a standard approach for use in absorption cell-based IR-spectrometric gas analysis Int. J. Spectrosc. 9132607

[247] Buchholz B and Ebert V 2014 Offsets in fiber-coupled diode laser hygrometers caused by parasitic absorption effects and their prevention Meas. Sci. Technol. 25075501

[248] Pogany A, Wagner S, Werhahn O and Ebert V 2015 Development and metrological characterization of a spectrometer for simultaneous, absolute measurement of carbon dioxide and water vapor in a wide concentration range Appl. Spectrosc. $69257-68$

[249] Nwaboh J, Persijn S, Arrhenius K, Bohlen H, Werhahn O and Ebert V 2018 Metrological quantification of CO in biogas using laser absorption spectroscopy and gas chromatography Meas. Sci. Technol. 29095010

[250] Buchholz B, Afchine A, Klein A, Schiller C, Kramer M and Ebert V 2017 A new airborne, absolute, twin dual-channel, multi-phase TDLAS-hygrometer: background, design, setup, and first flight data Atmos. Meas. Tech. 1035

[251] Merlone A et al 2015 The 'MeteoMet' project-metrology for meteorology: challenges and results Meteorol. Appl. 22 820-9

[252] Fahey D W et al 2014 The AquaVIT-1 intercomparison of atmospheric water vapor measurement techniques Atmos. Meas. Tech. 7 3177-213

[253] Wendisch M et al 2016 ACRIDICON-CHUVA campaign: studying tropical deep convective clouds and precipitation over amazonia using the New German research aircraft HALO Bull. Am. Meteorol. Soc. 97 1885-908

[254] Voigt C et al 2017 ML-CIRRUS - the airborne experiment on natural cirrus and contrail cirrus with the high-altitude long-range research aircraft HALO Bull. Am. Meteorol. Soc. 98 271-88

[255] Buchholz B, Bose N and Ebert V 2014 Absolute validation of a diode laser hygrometer via intercomparison with the German national primary water vapor standard Appl. Phys. B 116 883-99

[256] Buchholz B and Ebert V 2018 Absolute, pressure-dependent validation of a calibration-free, airborne laser hygrometer transfer standard (SEALDH-II) from 5 To $1200 \mathrm{ppmv}$ using a metrological humidity generator Atmos. Meas. Tech. 11 459-71

[257] Davis S P, Abrams M C and Brault J W 2001 Fourier Transform Spectrometry (New York: Academic)

[258] Griffiths P R and de Haseth J A 1996 Fourier Transform Infrared Spectrometry 2nd edn (New York: Wiley)

[259] Griffith D W T 1996 Synthetic calibration and quantitative analysis of gas phase infrared spectra Appl. Spectrosc. 50 59-70

[260] Haaland D M 1990 Multivariate calibration methods applied to quantitative FTIR analyses Practical Fourier Transform
Infrared Spectroscopy ed J R Ferraro and K Krishnan (San Diego, CA: Academic) pp 395-468

[261] Mohn J, Werner R A, Buchmann B and Emmenegger L 2007 High-precision $\delta^{13} \mathrm{CO}_{2}$ analysis by FTIR spectroscopy using a novel calibration strategy J. Mol. Struct. 834-6 95-101

[262] Griffith D W T, Deutscher N M, Caldow C, Kettlewell G, Riggenbach M and Hammer S 2012 A Fourier transform infrared trace gas and isotope analyser for atmospheric applications Atmos. Meas. Tech. 5 2481-98

[263] Esler M B, Griffith W T, Wilson S R and Steele L P 2000 Precision trace gas analysis by FT-IR spectroscopy 1 : simultaneous analysis of $\mathrm{CO}_{2}, \mathrm{CH}_{4}, \mathrm{~N}_{2} \mathrm{O}$ and $\mathrm{CO}$ in air Anal. Chem. 72 206-15

[264] Esler M B, Griffith D W T, Wilson S R and Steele L P 2000 Precision trace gas analysis by FT-IR spectroscopy 2: the ${ }^{13} \mathrm{C} /{ }^{12} \mathrm{C}$ isotope ratio of $\mathrm{CO}_{2}$ Anal. Chem. 72 216-21

[265] Esler M B and Griffith D W T 1998 Method and apparatus for measuring gas concentrations and isotope ratios in gases US Patent Specification 5838008A

[266] Mohn J, Zeeman M, Werner R A, Eugster W and Emmenegger L 2008 Continuous field measurements of $\delta^{13} \mathrm{C}-\mathrm{CO}_{2}$ and trace gases by FTIR spectroscopy Isot. Environ. Health Stud. 44 241-51

[267] Flores E, Viallon J, Moussay P, Idrees F and Wielgosz R I 2012 Highly accurate nitrogen dioxide $\left(\mathrm{NO}_{2}\right)$ in nitrogen standards based on permeation Anal. Chem. 84 20283-90

[268] Flores E et al 2012 Final report on international comparison CCQM-K74: nitrogen dioxide $10 \mu \mathrm{mol} \mathrm{mol}^{-1}$ Metrologia 4908005

[269] Flores E et al 2012 Final report of the pilot study CCQMP110-B1: a comparison of nitrogen dioxide $\left(\mathrm{NO}_{2}\right)$ in nitrogen standards at $10 \mu \mathrm{mol} \mathrm{mol}{ }^{-1}$ by Fourier transform infrared spectroscopy (FT-IR) Metrologia 4908006

[270] Viallon J et al 2017 CCQM-K90, formaldehyde in nitrogen, $2 \mu_{\mathrm{mol} \mathrm{mol}}^{-1}$ final report Metrologia 5408029

[271] Wielgosz R I et al 2008 Final report on CCQM-P73: international comparison of nitrogen monoxide in nitrogen gas standards (30-70) $\mu \mathrm{mol} \mathrm{mol}^{-1}$ Metrologia 4508002

[272] www.eumetrispec.org/eumetrispec.html (Accessed: December 2018)

[273] Flores E, Viallon J, Moussay P and Wielgosz R I 2012 Accurate measurements of nitrogen dioxide $\left(\mathrm{NO}_{2}\right)$ and nitric acid $\left(\mathrm{HNO}_{3}\right)$ mole fraction by FT-IR spectroscopy calibrated by gas standards and synthetic spectra Appl. Spectrosc. 671178

[274] Griffith D W T 2018 Calibration of isotopologue-specific optical trace gas analysers: a practical guide Atmos. Meas. Tech. 11 6189-201

[275] Wehr R, Munger J W, Nelson D D, McManus J B, Zahniser M S, Wofsy S C and Saleska S R 2013 Long-term eddy covariance measurements of the isotopic composition of the ecosystem-atmosphere exchange of $\mathrm{CO}_{2}$ in a temperate forest Agric. Forest Meteorol. 181 69-84 